University of Wollongong

Research Online

Faculty of Engineering and Information

Faculty of Engineering and Information

Sciences - Papers: Part B

Sciences

2018

Experimental Investigation on the Effect of Corrosion on the Bond Between Reinforcing Steel Bars and Fibre Reinforced Geopolymer Concrete

Nabeel Farhan

University of Wollongong, naf010@uowmail.edu.au

M Neaz Sheikh

University of Wollongong, msheikh@uow.edu.au

Muhammad N. S Hadi

University of Wollongong, mhadi@uow.edu.au

Follow this and additional works at: https://ro.uow.edu.au/eispapers1

Part of the Engineering Commons, and the Science and Technology Studies Commons

Research Online is the open access institutional repository for the University of Wollongong. For further information contact the UOW Library: research-pubs@uow.edu.au 


\title{
Experimental Investigation on the Effect of Corrosion on the Bond Between Reinforcing Steel Bars and Fibre Reinforced Geopolymer Concrete
}

\author{
Abstract \\ This paper investigates the effect of corrosion on the bond between reinforcing steel bars and fibre \\ reinforced geopolymer concrete. An accelerated corrosion method was used to corrode the reinforcing \\ steel bars embedded in geopolymer concrete. Three types of steel fibres including straight micro steel \\ fibre, deformed macro steel fibre, and hybrid steel fibre were used in this study. A total of ten geopolymer \\ concrete mixes were used to evaluate the effect of corrosion of steel bar on the bond between steel bar \\ and fibre reinforced geopolymer concrete. The pull-out test specimens were composed of concrete cubes \\ with a side length of $160 \mathrm{~mm}$ and reinforced with a deformed steel bar of $16 \mathrm{~mm}$ diameter located at the \\ centre of the specimens. The test results showed that the addition of steel fibres in geopolymer concrete \\ (fibre reinforced geopolymer concrete) significantly enhanced the bond strength of reinforcing steel bar. \\ The bond strength of reinforcing steel bars embedded in steel fibre reinforced geopolymer concrete \\ specimens reduced due to corrosion of reinforcement. However, the reduction of bond strength in steel \\ fibre reinforced geopolymer concrete specimens was less than the reduction of bond strength in plain \\ geopolymer concrete specimen. \\ Disciplines \\ Engineering | Science and Technology Studies

\section{Publication Details} \\ Farhan, N. A., Sheikh, M. Neaz. \& Hadi, M. N. S. (2018). Experimental Investigation on the Effect of \\ Corrosion on the Bond Between Reinforcing Steel Bars and Fibre Reinforced Geopolymer Concrete. \\ Structures, 14 251-261.
}


1 Experimental Investigation on the Effect of Corrosion on the Bond between

2

3

4

5

6

7

8

9

10

11

12

13

14

15

16

17

18

19

20

21

22

23

24

25

9

\section{Reinforcing Steel Bars and Fibre Reinforced Geopolymer Concrete}

\author{
Nabeel A. Farhan ${ }^{1}$, M. Neaz Sheikh², Muhammad N.S. Hadi ${ }^{3 *}$, \\ ${ }^{1}$ Ph.D. Candidate, School of Civil, Mining and Environmental Engineering, University of \\ Wollongong, Australia \\ ${ }^{2}$ Associate Professor, School of Civil, Mining and Environmental Engineering, University of \\ Wollongong, Australia \\ ${ }^{3 *}$ Associate Professor, School of Civil, Mining and Environmental Engineering, University of \\ Wollongong, Australia
}

Correspondence:

Muhammad N. S. Hadi

School of Civil, Mining \& Environmental Engineering

University of Wollongong, Australia

E-mail:mhadi@uow.edu.au

Telephone: + 61242214762

Facsimiles: + 61242213238

* Corresponding author 


\section{Experimental Investigation on the Effect of Corrosion on the Bond between Reinforcing Steel Bars and Fibre Reinforced Geopolymer Concrete}

\section{Abstract}

This paper investigates the effect of corrosion on the bond between reinforcing steel bars and fibre reinforced geopolymer concrete. An accelerated corrosion method was used to corrode the reinforcing steel bars embedded in geopolymer concrete. Three types of steel fibres including straight micro steel fibre, deformed macro steel fibre, and hybrid steel fibre were used in this study. A total of ten geopolymer concrete mixes were used to evaluate the effect of corrosion of steel bar on the bond between steel bar and fibre reinforced geopolymer concrete. The pull-out test specimens were composed of concrete cubes with a side length of $160 \mathrm{~mm}$ and reinforced with a deformed steel bar of $16 \mathrm{~mm}$ diameter located at the centre of the specimens. The test results showed that the addition of steel fibres in geopolymer concrete (fibre reinforced geopolymer concrete) significantly enhanced the bond strength of reinforcing steel bar. The bond strength of reinforcing steel bars embedded in steel fibre reinforced geopolymer concrete specimens reduced due to corrosion of reinforcement. However, the reduction of bond strength in steel fibre reinforced geopolymer concrete specimens was less than the reduction of bond strength in plain geopolymer concrete specimen.

Keywords: Corrosion; Bond; Geopolymer; Steel Fibres; Pull-out 


\section{Introduction}

50 The process of the production of cement is associated with high energy consumption causing

51 adverse environmental impact. It was estimated that the production of one tonne of cement requires about one tonne of raw materials and emits nearly one tonne of carbon dioxide $\left(\mathrm{CO}_{2}\right)$ into the atmosphere [1-3]. Hence, to reduce the adverse environmental impact associated with the production of cement, the use of alternative binders to cement such as industrial byproducts are considered an attractive solution to reduce or alleviate adverse environmental impacts. During the last few decades, research investigations were carried out into the use of geopolymer concrete as an alternative to the Ordinary Portland Cement (OPC) concrete.

Geopolymer concrete consumes lower energy and causes low carbon dioxide emissions into the atmosphere. It possesses high early strength, high fire resistance and high durability against chemical attack. It has been a promising material to be used in different construction applications as an alternative to OPC concrete [4-7]. On the other hand, low tensile and flexural strengths are the main drawbacks limiting the use of geopolymer concrete in several applications including the construction of columns and beams. The addition of steel fibres was found to be a promising solution to enhance the tensile and flexural strengths of geopolymer concrete [8]. $\mathrm{Ng}$ et al. [9] found that shear strength of geopolymer concrete beams increased with the addition of steel fibre. Bernal et al. [10] investigated the mechanical properties and durability performance of heat cured geopolymer concrete reinforced with various proportions of steel fibre ranging from 0 to $3 \%$ by volume. The test results showed a reduction of the compressive strength with the addition of steel fibres. However, splitting tensile strength and flexural strength were significantly improved with the increase in the 
water absorption, capillarity and water penetration resistance were enhanced with the addition steel fibres in the heat cured geopolymer concrete [10].

74 A large number of reinforced concrete structures are exposed to chloride attack leading to the corrosion of reinforcing steel bars [11]. The corrosion of the steel bar has significant adverse effects on the durability and serviceability of the reinforced concrete (RC) structures [12]. Several research studies reported that the corrosion of the steel bar in RC structures reduced the tensile strength of the reinforcing bars because of the loss of the cross-sectional area and loss in the bond performance between reinforcing steel bar and surrounding concrete [13, 14]. Abosrra et al. [15] studied the effect of corrosion on the bond behaviour of deformed steel bars embedded in concrete with different compressive strengths. The test results showed that higher compressive strength of concrete increased the bond strength and reduced the rate of corrosion of steel reinforcing bar.

Steel fibres are commonly used for reinforcing the precast elements, hydraulic structures, airfield pavements, and tunnel lining segments. However, steel fibres cannot be used to replace the conventional reinforcing steel bars in most concrete members. Steel fibres are used as complementary to the conventional reinforcing steel bars in RC structures. However, some studies recommended for not using steel fibre in combination with conventional reinforcing steel bars in saltwater environments because of the concerns that steel fibres might accelerate the corrosion of reinforcing steel bars in RC structures [16, 17].

Roque et al. [18] studied the durability of hooked end steel fibre of RC structural members. The test results showed that steel fibres improved the durability of RC structures in nonsubmerged saltwater environments. It was recommended that steel fibres should not be used in combination with reinforcing steel bars in seawater environments because steel fibres in contact with reinforcing steel bars accelerated the corrosion of the reinforcing steel bars [18]. 
96 Grubb et al. [19] investigated the effect of micro steel fibres on the corrosion of reinforcing

97 steel bars. Mortar specimens with and without micro steel fibres were exposed to a corrosive environment. Steel bars embedded in mortar reinforced with micro steel fibres showed better resistance to corrosion than steel bars embedded in plain mortar. Someh and Saeki [20] studied the durability of concrete reinforced by zinc-coated steel fibres. Steel bars embedded in zinc-coated steel fibre reinforced concrete remained free from corrosion for a longer period of time compared to steel bar embedded in plain concrete when exposed to similar corrosive environments.

Sofi et al. [21] investigated the bond strength of geopolymer concrete with reinforcing steel bar. The test results showed that all specimens failed by splitting of geopolymer concrete surrounding the steel bar and the bond strength increased with a decrease in the diameter of the reinforcing steel bar. The bond strength of geopolymer concrete and OPC concrete with reinforcing steel bars was also studied by Sarker [22]. The test results showed that both geopolymer concrete and OPC concrete specimens failed by splitting of concrete around the region bonded with the reinforcing steel bar. The test results also showed that geopolymer concrete had higher bond strength than OPC concrete with reinforcing steel bars [22]. Castel and Foster [23] also reported that the bond strength of reinforcing steel bar embedded in the geopolymer concrete was slightly higher than the bond strength of reinforcing steel bar embedded in the OPC concrete.

Different test methods were adopted in the previous research studies for measuring the bond between reinforcing steel bars and concrete including pull-out test [21], beam end test [22], beam anchorage test [24] and splice test [25]. In this study, the pull-out test was used because of the ease of fabrication and the simplicity of the test. Several research studies investigated the bond of reinforcing steel bars embedded in geopolymer concrete. However, the effect of 
corrosion on the bond performance of reinforcing steel bars embedded in steel fibre reinforced geopolymer concrete has not yet been investigated. The objective of this study, therefore, is to evaluate the effect of corrosion on the bond between steel bars and fibre reinforced geopolymer concrete. The objective of this study is achieved through extensive experimental investigations. The development of a mathematical model is considered beyond the scope of this paper.

\section{Experimental program}

\subsection{Materials}

The materials used in this study included ground granulated blast furnace slag (GGBS) and fly ash (FA). The GGBS was used as the source of aluminosilicate materials for the production of geopolymer concrete and the FA was used as an additive to increase the setting time of geopolymer concrete under ambient curing conditions. The GGBS was supplied by the Australian Slag Association [26]. The FA was supplied by Eraring Power Station, Australia [27]. The X-Ray Fluorescent (XRF) was used to analyse the chemical composition of FA and GGBS. The chemical composition analysis of GGBS and FA was conducted in the School of Earth Science at the University of Wollongong Australia. The chemical compositions of GGBS and FA are shown in Table 1. The results of XRF classified the FA as low calcium FA (Type F) according to ASTM C618-08 [28]. The sum of $\mathrm{SiO}_{2}, \mathrm{Al}_{2} \mathrm{O}$ and $\mathrm{Fe}_{2} \mathrm{O}_{3}$ content were higher than $70 \%$ of the FA components. The $\mathrm{CaO}$ content was less than $8 \%$ of the FA components. Coarse aggregate with a maximum size of $10 \mathrm{~mm}$ and river sand as a fine aggregate were used in this study.

The roles of alkaline activator solution are to dissolve the reactive portion of the source materials (aluminate (Al) and silicate (Si)) present in GGBS and FA and to provide a high alkaline liquid medium. The alkaline activator solution was a blend of sodium hydroxide 
$(\mathrm{NaOH})$ and sodium silicate $\left(\mathrm{Na}_{2} \mathrm{SiO}_{3}\right)$ solutions. The sodium hydroxide $(\mathrm{NaOH})$ solution was prepared by dissolving caustic soda pellets in potable water. The $\mathrm{NaOH}$ solution was

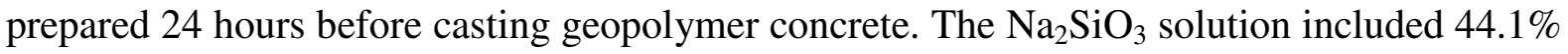
solids, $29.4 \%$ silicate and $14.7 \%$ sodium oxide. The $\mathrm{Na}_{2} \mathrm{SiO}_{3}$ was supplied by PQ Australia [29]. High range water reducer (Glenium 8700) supplied by BASF Australia [30] was used to improve the workability of the geopolymer concrete.

In this study, three types of steel fibres were used: straight micro steel (MIS) fibres, deformed macro steel (DES) fibres and hybrid steel (HYS) fibres. The straight micro steel (MIS) fibres were $6 \mathrm{~mm}$ in length and $0.2 \mathrm{~mm}$ in diameter with a tensile strength of $2600 \mathrm{MPa}$ [31]. The deformed macro steel (DES) fibres were $18 \mathrm{~mm}$ in length and $0.55 \mathrm{~mm}$ in diameter with a tensile strength of $800 \mathrm{MPa}$ [32]. The HYS fibres were a combination of MIS fibres and DES fibres. The MIS fibres were supplied by Ganzhou Daye Metallic Fibres Company, China [31]. The DES fibres were supplied by Fibercon Company, Australia [32]. The properties of steel fibres are presented in Table 2. Deformed steel bars of $16 \mathrm{~mm}$ diameter were used as reinforcement. Five samples of $16 \mathrm{~mm}$ deformed steel bars were tested according to AS13912007 [33]. The deformed steel bars have two longitudinal ribs and rows of alternately inclined transverse ribs on both sides of the bars. These ribs contribute positively to the bond strength between reinforcing steel bar and concrete. The average yield tensile strength and corresponding yield strain of the deformed steel bar were $612 \mathrm{MPa}$ and $0.003 \mathrm{~mm} / \mathrm{mm}$, respectively.

\subsection{Preparation of concrete sample}

A total of ten geopolymer concrete mixes were used to evaluate the effect of the corrosion on the bond between reinforcing steel bars and geopolymer concrete. The bond was evaluated using pull-out tests. The dimensions of the specimens were chosen according to the European 
Standard pull-out test EN-10080 [34], as shown in Fig. 1. The pull-out test specimens were geopolymer concrete cube specimens with a side length of $160 \mathrm{~mm}$ and reinforced centrally with a $16 \mathrm{~mm}$ diameter deformed steel bar. The length of the steel bar was $510 \mathrm{~mm}$ in order to facilitate the loading of the specimen using the $500 \mathrm{kN}$ Universal Instron testing machine. The bonded length of the tested steel bar in the specimens was five times the diameter of the steel bar (i.e., $80 \mathrm{~mm}$ ), as shown in Fig. 1. The unbounded length of the steel bar in the specimen was obtained by using a polyvinyl chloride (PVC) pipe at one end of the specimens (Fig. 2). Before mixing of concrete, the deformed steel bars were carefully cleaned and the mass of the deformed steel bars in each specimen was recorded.

In this study, three types of moulds were used. Plywood moulds were used for preparing pullout test specimens. Polyvinyl chloride (PVC) cylindrical moulds of $100 \mathrm{~mm}$ diameter and $200 \mathrm{~mm}$ length were used for preparing concrete cylinders to measure the compressive strength of concrete. Also, PVC cylindrical moulds of $150 \mathrm{~mm}$ diameter and $300 \mathrm{~mm}$ length were used for preparing concrete cylinders to measure the splitting tensile strength of concrete. Table 3 shows the mix proportion of geopolymer concrete which was adopted from a previous study by Hadi et al. [35]. The dry materials including binder (GGBS+FA), coarse and fine aggregate were first mixed for about 3 minutes. Afterwards, alkaline activator (combination sodium hydroxide with sodium silicate) was slowly added into the mixer together with the superplasticiser and water. The mixing continued for another 5 minutes. The geopolymer concrete mix was poured from the pan mixer into plywood moulds prepared for plain geopolymer concrete specimens. For the fibre reinforced geopolymer concrete specimens, after the dry materials and liquid components were mixed thoroughly, steel fibres were added gradually to the wet mix. Mixing continued until the steel fibres were well dispersed in the geopolymer concrete mixes. Adequate care was taken during the mixing to ensure a uniform distribution of the steel fibres in the geopolymer concrete mixes. 
The geopolymer concrete was poured into the plywood moulds prepared for the geopolymer concrete specimens. The geopolymer concrete specimens were cast and compacted in three stages. Each stage was internally vibrated using an electric vibrator to remove air voids and to compact the fresh concrete. Afterwards, the geopolymer concrete specimens were kept in the moulds for 24 hours. The specimens were then demoulded and kept under ambient conditions until age of 28 days.

\subsection{Labelling system}

In this study, each concrete mix has been identified with an acronym (Table 4). The symbol GC refers to plain geopolymer concrete. The symbols GCMIS and GCDES refer to geopolymer concrete reinforced with straight micro and deformed macro steel fibres, respectively. The numbers $(1,1.5$, and 2$)$ afterwards refer to the percentages of steel fibres by volume used in this study. The symbol GCHYS refers to geopolymer concrete with hybrid steel fibres. The GCHYS mixes included combinations of micro steel and deformed steel fibres in different proportions. In this study, the GCHYS mixes included $2 \%$ hybrid steel fibres by volume. The GCHYS2a included $0.5 \%$ micro steel fibres and $1.5 \%$ deformed steel fibres $(0.5 \% \mathrm{MIS}+1.5 \% \mathrm{DES})$, GCHYS $2 \mathrm{~b}$ included $1 \%$ micro steel fibres and $1 \%$ deformed steel fibres (1\%MIS+1\%DES) and GCHYS2c included 1.5\% micro steel fibres and $0.5 \%$ deformed steel fibres (1.5\%MIS+0.5\%DES).

\subsection{Accelerated corrosion method}

In this study, an electrochemical method was used to accelerate the corrosion of deformed steel bars. The specimens were submerged in a plastic tank filled with sea water for three days before being exposed to an accelerated corrosion process to ensure full saturation of the tested specimen [36]. The accelerated corrosion process was obtained using a direct current 
216 (D.C.) supply providing 30 Volt constant potential at 0 to 4 Amperes (Amp). The direct 217 current was applied to the steel bars embedded in the concrete using the steel bars as the

218

219 anode. The cathode was made from a galvanised mesh, which was placed around the specimens in the salt solution. The current passed from the steel bars to the galvanised mesh placed inside the salt solution. The end of the steel bar was insulated during the corrosion in order to ensure that only the bonded zone would be corroded. One end of the steel bar was coated with paraffin and wrapped with an insulating plastic membrane. A cushion made from PVC was also used under the specimens to insulate the specimens from the base of the plastic tank. The schematic of the accelerated corrosion set-up is shown in Fig. 3. The experimental setup for the accelerated corrosion process is shown in Fig. 4. The calculated mass loss of the steel bars due to corrosion was calculated according to Faraday's law using Equation (1) [37, 38].

Mass loss $=\frac{t \times I \times 55.847}{2 \times 96487}$

where $t$ is the duration of exposure (hour) and $I$ is the average current to which the reinforcing bar was exposed. The actual mass loss of the steel bars due to corrosion was calculated using Equation (2) [37, 38].

$$
\text { Mass loss }=\frac{G_{0}-G_{1}}{G_{0}} \times 100 \%
$$

where $G_{0}$ is the initial weight of the steel bars before corrosion and $G_{1}$ is the weight of the steel bar at the end of the test. Badawi and Soudki [39] and El Maaddawy and Soudki [40] observed that the use of current density for accelerated corrosion tests provided a similar result estimated by Faraday's law equations, as presented in Equation (1).

\subsection{Testing of specimens}


238 The compressive strength tests of geopolymer concrete specimens were carried out according to AS 1012.9-1999 [41] at 28 days. A compression testing machine with a capacity of 1800 $\mathrm{kN}$ was used to conduct the compressive strength tests. The splitting tensile strength tests of geopolymer concrete specimens were performed according to AS 1012.10-2000 [42] at 28 days. The specimens were tested at the loading rate of $106 \mathrm{kN} / \mathrm{min}$ until the specimen failed.

243 The concentric pull-out tests were performed for the corroded and non-corroded specimens 244 according to EN-10080 [34]. The pull-out tests were performed using a $500 \mathrm{kN}$ Universal Instron testing machine, as shown in Fig. 5. A specially designed loading frame was used for the pull-out test. The loading frame consisted of two plates in which the bottom plate was clamped to the base of the universal Instron testing machine. The reinforcing steel bar passing through the central hole of the top plate was clamped to the upper head of testing machine (Fig. 5). The specimens were tested up to failure with a displacement controlled loading at $0.1 \mathrm{~mm} / \mathrm{min}$. The data were recorded at every two seconds. None of the reinforcing steel bars reached the yield strength during the tests. The axial loads applied by the testing machine were recorded to establish the bond stress. The bond stress was computed from the applied axial loads on the steel bar divided by the surface area of the embedded length of the reinforcing steel bar using Equation (3).

$$
\tau=\frac{P}{\pi \times D \times L}
$$
of the reinforcing steel bars, respectively.

\section{Results and discussions}

\subsection{Mechanical properties}


The average compressive strength and average splitting tensile strength of all concrete mixes are presented in Table 5. For each mix, three specimens for the compressive strength and three specimens for the splitting tensile strength were tested and the average results have been reported. It can be seen in Table 5 that the average compressive strengths and average splitting tensile strengths of GC specimens were lower than the average compressive and average splitting tensile strengths of geopolymer concrete specimens with different types of steel fibre.

The average compressive strength was found to be $41.1 \mathrm{MPa}$ for the GC specimens at 28 days. It can be observed that the increase of MIS fibre content from 0 to $2 \%$ by volume, the average compressive strength of the geopolymer concrete increased by $6.3 \%$. With the increase of DES fibre content from 0 to $2 \%$ by volume, the average compressive strength of the geopolymer concrete increased by 3.6\%. The addition of HYS fibres also increased the average compressive strength of the geopolymer concrete. The enhancement in the average compressive strength of the HYS fibre reinforced geopolymer concrete ranged from $11.9 \%$ to 14.8\%. Specimens GHYS2b (1\%MIS+1\%DES) achieved the highest average compressive strength. The increase in the compressive strength of geopolymer concrete with the addition of steel fibre can be attributed to the role of the steel fibre in bridging the cracks, which restrained the initiation and propagation of cracks.

The average splitting tensile strength of the GC specimens was $3.7 \mathrm{MPa}$ for 28 days (Table 5). For the increase of MIS fibre content from 0 to $2 \%$ by volume, the average splitting tensile strength of the geopolymer concrete increased by $37.8 \%$. For the increase of DES fibre content from 0 to $2 \%$ by volume, the average splitting tensile strength of the geopolymer concrete increased by $43.2 \%$. Finally, the addition of $2 \%$ HYS fibre by volume significantly increased the splitting tensile strength. The improvements in the average 
splitting tensile strength ranged from $51.4 \%$ to $64.8 \%$. The highest average splitting tensile strength of the geopolymer concrete was achieved for GCHYS2b (1\%MIS+1\%DES) specimens. The increase in the splitting tensile strength with the addition of the steel fibre is attributed to the uniform distribution of steel fibre throughout the geopolymer concrete mixes. Consequently, greater efficiencies in delaying the initiation and propagation of cracks were achieved, which improved the splitting tensile strength of reinforced geopolymer concrete.

\subsection{Corrosion and cracking behaviour}

In the corrosion process, the electrical potential applied to the positively charged steel bars attracts negatively charged chloride ions from the salt solution into the concrete. When the chloride ions reached the steel bar, the surface of steel bars began to corrode [43]. The specimens were monitored to determine the beginning of the corrosion of steel bars. Figure 6 shows the variation of current applied with time in GC and steel fibre reinforced geopolymer concrete specimens.

The variation of applied current with time was obtained by calculating the average current at every 24 hour using Digitech QM1575 Multimeter. Figure 6a indicates that the average current in the Specimen GC decreased from $440 \mathrm{~mA}$ to $145 \mathrm{~mA}$ in 96 hours. Afterwards, the current increased from $145 \mathrm{~mA}$ to $180 \mathrm{~mA}$ during the next 48 hours. The Specimen GC showed ferrous oxides (brown rust) on the top of the specimens after 240 hours of accelerated corrosion exposure. On the other hand, the average current of the steel fibre reinforced geopolymer concrete specimens decreased for about 96 hours and remained nearly steady for about 500 hours. Afterwards, the average current increased. The MIS fibre reinforced geopolymer concrete specimen showed no sign of brown rust for the same period (after 240 hours of accelerated corrosion exposure). As the experiment continued, ferrous oxides 
(brown rusts) were observed on the top of the MIS fibre reinforced geopolymer concrete specimens after about 400 hours. The brown rust stains seen on the top of the specimens indicated the beginning of corrosion in the embedded steel bars. Figures 6 (a-c) shows that the trends of the current for the steel fibre (MIS, DES and HYS) reinforced geopolymer concrete specimens were almost similar. The possible reason for the initial decreases in the current was due to the filling of the pores in the concrete by salt and other deposits of the salt water. The increase in the current flow indicated the beginning of the corrosion of reinforcing bar. It can be observed that the initial current readings recorded for the steel fibre reinforced geopolymer concrete specimens were lower than the current readings recorded for Specimen GC. The current readings for geopolymer concrete specimens did not show any significant increase during the accelerated corrosion process. This indicates that the steel fibre reinforced geopolymer concrete demonstrated better resistance against chloride penetration than the Specimen GC.

Initial cracks were observed on the bottom of Specimen GC after about 240 hours of accelerated corrosion. On the other hand, the initial cracks were observed on the bottom of specimens after about 500 hours of accelerated corrosion of steel fibre reinforced geopolymer concrete specimens. The cracking started with increasing the current in the power supply, where the current increased from 1.6 Amp to 3.9 Amp.

At the end of the accelerated corrosion process, all specimens exhibited longitudinal cracks running parallel to the steel bars. The maximum measured crack width was in the range of 0.15-0.25 mm and the crack depth was in the range of $1.5-4.5 \mathrm{~mm}$ for the Specimen GC. However, only micro cracks were noticed on the steel fibre reinforced geopolymer concrete specimens. The accelerated corrosion test was stopped at 600 hours. It is apparent that the steel fibre reinforced geopolymer concrete specimens demonstrate better resistance against 
chloride penetration compared to the Specimen GC in a corrosive environment. The specimens were removed from the tank for visual inspection and pull-out testing.

\subsection{Mass loss measurement}

The level of corrosion in the embedded steel bar was determined from the mass loss measurement. The level corrosion in terms of the mass loss of the corroded steel bar due to corrosion were first estimated based on Faraday's law using Equation (1). The electric current and the time of corrosion in the accelerated corrosion test was calculated from Equation (1) based on the calculated mass loss. The accelerated corrosion test was stopped at 600 hours due to the sudden increases in the current reading, which occurred with the cracking at the bottom of the specimens. The actual corrosion levels were measured by the mass loss of the corroded steel bar using Equation (2). At the end of the test, the corroded steel bars were retrieved to determine the mass loss. The corroded steel bars for each specimen were cleaned in order to remove all corrosion residues before weighing. The corroded steel bars were cleaned with deionized water using a metal brush in order to ensure that the steel bars were free from any corrosion residue. Figure 7 shows the steel bars before and after corrosion. The steel bars were weighed and the percentage of mass loss was computed using Equation (2).

The specimens with the highest volume fraction (2\%) of MIS, DES and HYS (1\%MIS+1\%DES) steel fibres together with steel bars before and after corrosion process are shown in Fig. 8. It can be observed from Fig. 8 that the steel bars embedded in Specimen GC noticeably suffered from corrosion damage. On the other hand, the steel bars embedded in steel fibre reinforced geopolymer concrete specimens had lower corrosion effects. The measured corrosion levels and calculated corrosion levels are reported in Table 6. It can be seen from Table 6 that the measured corrosion levels were lower than the calculated corrosion levels. The difference in measured corrosion levels and the calculated corrosion 
levels can be attributed to the fact that the permeability of the concrete played an important

357 role in the actual level of corrosion. The permeability of the concrete was not included in

358 Equation (1) for the calculation of the theoretical level of corrosion. Although the specimens

359 were immersed in the water for three days prior to the accelerated corrosion process, it would

360 have taken a longer period for the saltwater to reach the steel reinforcing bar [36].

361 Based on the test results, the percentage mass losses of the corroded steel bar were $5.90 \%$ for

362 Specimen GC. On the other hand, for the steel fibre reinforced geopolymer concrete specimens, there was a slight mass loss of corroded steel bars after 600 hours of accelerated corrosion testing. Hence, the steel fibre reinforced geopolymer concrete exhibited better corrosion resistance in the marine environment compared to the plain geopolymer concrete. The addition of steel fibres to the geopolymer concrete provided positive effects on the control of the corrosion of steel bar and concrete cracking. Steel fibres in geopolymer concrete led to smaller and more closely spaced cracks, resulting in reduced permeability of the concrete. Also, Specimen GC showed higher mass loss of the corroded steel bar due to the formation of wide cracks on the bottom of the specimens (Fig. 8). The cracks allowed the chloride ions to reach the steel bar quicker and accelerated the rate of corrosion.

\subsection{Bond failure modes}

373 Figure 9 shows the failure patterns of specimens after the pull-out tests. It can be observed that the bond failure of non-corroded specimens was almost similar, except Specimen GC.

375 The failure of the steel fibre (MIS, DES and HYS) reinforced geopolymer concrete specimens occurred by splitting cracks during the pull-out test while the failure of Specimen

377 GC occurred by pull-out failure. The typical splitting cracks of the steel fibre reinforced geopolymer concrete specimens started from the loading end and extended to the free end. 
379 For corroded specimens, the bond failure of Specimen GC was caused by newly generated splitting cracks around the steel bar in addition to the existing corrosion induced longitudinal cracks. This is because of the brittle behaviour of Specimen GC (without steel fibre) due to the corrosion of steel bar. Thus, more cracks generated when sudden loss of bond strength occurred. The steel fibre reinforced geopolymer concrete specimens failed because of the widening of the existing longitudinal crack due to corrosion. The splitting cracks generated or existing longitudinal cracks widened continuously from the loading end to the free end. After the pull-out test, only slip of the steel fibres has been observed.

\subsection{Bond versus free-end slip behaviour}

Results of pull-out tests are shown in Table 7. The axial load and free-end slip were obtained directly from the $500 \mathrm{kN}$ Universal Instron testing machine. To record the axial load and the free-end slip, an electronic data acquisition system was used.

The behaviour of of bond stress versus free-end slip comprises three stages as shown in Fig. 10. In the first stage (stage I), the bond stress increased until the chemical adhesion is exhausted and slips occurred between the steel bar and the concrete. This stage is limited by the tensile strength of the concrete. The bond stress-slip response remains linear during the first stage. In the second stage (stage II), when the applied axial load increased towards the maximum bond stress, the rate of slip started to increase and the bond stress-slip response became distinctly non-linear. The second stage corresponds to the occurrence of microcracking in the concrete specimens. In the last stage (stage III), the specimen reached the maximum bond stress and some longitudinal splitting cracks developed parallel to the steel bar. In this stage, the bond stress decreased with the increase of the slip. 
Figure 11 shows typical bond stress versus free end slip for non-corroded concrete

402

403

404

405

406

407

408

409

410

411

412

413

414

415

416

417

418

419

420

421

422

423

424

425 specimens. It can be seen from Fig. 11 that the maximum bond stress of non-corroded Specimen GC was $16.46 \mathrm{MPa}$ with a corresponding slip of $1.96 \mathrm{~mm}$. The addition of MIS, DES and HYS fibres to the geopolymer concrete increased the maximum bond stress and the corresponding slip (Table 7). The addition of $1 \%, 1.5 \%$ and $2 \%$ by volume of MIS fibre increased the maximum bond stress by $28.3 \%, 32.9 \%$ and $38.3 \%$, respectively. The addition $1 \%, 1.5 \%$ and $2 \%$ by volume of DES fibre increased the maximum bond stress by $24.9 \%$, $28.9 \%$ and $32.8 \%$, respectively. Also, the addition of MIS and DES fibre increased the slip corresponding to the maximum bond stress noticeably. The slip corresponding to the maximum bond stress of fibre reinforced geopolymer concrete with MIS fibre of $1 \%, 1.5 \%$ and $2 \%$ by volume increased by $25.5 \%, 30.1 \%$ and $52.1 \%$, respectively. The slip corresponding to the maximum bond stress of fibre reinforced geopolymer concrete with DES fibre of $1 \%, 1.5 \%$ and $2 \%$ by volume increased by $24.5 \%, 32.7 \%$ and $36.7 \%$, respectively. Finally, the addition of hybrid steel fibre increased the maximum bond stress significantly. The improvement of the bond stress ranged from 39\% (GCHYS2a) to 65.9\% (GCHYS2b). Specimen GCHYS2b achieved the highest bond stress of geopolymer concrete. The slip corresponding to the maximum bond stress of Specimen GCHYS2b was $71.4 \%$ higher than the slip corresponding to the maximum bond stress of Specimen GC. It is apparent that the highest increase in the bond stress of geopolymer concrete was achieved by the addition of HYS fibre. This is due to the highest increase in the strength of geopolymer concrete as a result of the addition of HYS fibre, which affected the bond strength of the geopolymer concrete effectively.

The bond stress of all the specimens was adversely affected by the corrosion of reinforcing steel bar. The effect of corrosion on the bond stress versus free-end slip are shown in Fig. 12. It can be seen that the bond stress of Specimen GC noticeably dropped due to the loss of 
interlocking action between the corroded steel reinforcing bar and concrete. The maximum

427 bond stress of Specimen GC was 5.85 MPa with the corresponding slip of $1.35 \mathrm{~mm}$. It was

428

429

430

431

432

433

434

435

436

437

438

439

440

441

442

443

444

445

446

447 Finally, the addition of HYS fibre increased the maximum bond stress significantly. The

observed that the reduction in the bond stress of Specimen GC was greater than the reduction in the bond stress of the steel fibre reinforced geopolymer concrete specimens under the same corrosion condition. This indicates that the steel fibre reinforced geopolymer concrete specimens exhibited better corrosion resistance compared to Specimen GC. The main reason for the higher losses of the bond stress of Specimen GC might be due to the wide longitudinal cracks that were developed on the specimens, which allowed chloride ions to penetrate quickly into the concrete and accelerate the rate of corrosion.

The maximum bond stress of fibre reinforced geopolymer concrete with MIS fibre of $1 \%$, $1.5 \%$ and $2 \%$ by volume increased by $41.9 \%, 53.5 \%$ and $75.38 \%$, respectively, compared to Specimen GC. The strain corresponding to the maximum bond stress of fibre reinforced geopolymer concrete with MIS fibre of $1 \%, 1.5 \%$ and $2 \%$ by volume increased by $49.6 \%$, $71.8 \%$ and $114.1 \%$, respectively. Also, the addition of DES fibre to the geopolymer concrete with $1 \%, 1.5 \%$ and $2 \%$ by volume increased the maximum bond stress by about $26.2 \%$, $31.3 \%$ and $47.5 \%$, respectively, compared to Specimen GC. The strain corresponding to the maximum bond stress of fibre reinforced geopolymer concrete with DES fibre of $1 \%, 1.5 \%$ and $2 \%$ by volume increased by $5.2 \%, 9.6 \%$ and $58.5 \%$, respectively. In general, the addition of steel fibre in the geopolymer concrete resulted in an increase in the bond stress. This might be due to the fact that the formation of corrosion on the surface of steel fibres increased the friction between the steel fibre and the geopolymer concrete.

improvement of the bond stress ranged from $83.8 \%$ (Specimen GCHYS2a) to $185.6 \%$ (Specimen GCHYS2b). The highest bond stress of geopolymer concrete was achieved by 
Specimen GCHYS2b. The slip corresponding to the maximum bond stress was increased by

$451 \quad 138.5 \%$. It can be seen from Fig. 12 that the HYS fibre reinforced geopolymer concrete with $1 \%$ MIS and 1\% DES achieved the highest bond stress for corroded specimens compared to the geopolymer concrete specimens with other types of steel fibres. This can be attributed to 454 the high volume fraction of steel fibres with different shapes and sizes which led to the increase in the availability of fibres crossing the cracked section. Hence, greater efficiency in delaying the growth of micro and macro cracks was obtained. Therefore, the highest improvement in the bond stress of geopolymer concrete specimens with HYS fibres was achieved.

\section{Conclusions}

An experimental study was carried out to evaluate the effect of corrosion on the bond behaviour of reinforcing steel bars embedded in steel fibre reinforced geopolymer concrete. Based on the results of the experimental investigations, the following conclusions can be drawn:

1. The addition of MIS, DES, and HYS fibres significantly improved the compressive strength and splitting tensile strength of geopolymer concrete mixes. The addition of $2 \%$ HYS (1\% MIS and 1\% DES) fibre by volume achieved the highest compressive strength and

467 splitting tensile strength. All steel fibre reinforced geopolymer concrete specimens failed due to the splitting of concrete along the bonded length of reinforcing steel bar. The splitting failure occurred when the reinforcing steel bar reached the peak axial load, and cracks generated parallel to the applied axial load on the front face of the specimens as the bar

471 pulled out. The failure of control plain geopolymer concrete specimen occurred due to the 472 pull-out of the reinforcing steel bar. The pull-out failure occurred when the reinforcing steel 
473 bar reached the peak axial load and pulled out from the specimen without splitting on any 474 face of the concrete.

475 2. Due to accelerated corrosion process, the maximum measured cracks width was in the range of $0.15-0.25 \mathrm{~mm}$ and maximum measured crack depth was in the range of 1.5-4.5 mm

477 for control plain geopolymer concrete specimen. However, only micro cracks were noticed 478 on the steel fibre reinforced geopolymer concrete specimens.

479 3. The steel fibre reinforced geopolymer concrete specimens showed good resistance to chloride attack than control plain geopolymer concrete specimen. The addition of steel fibres to the geopolymer concrete significantly enhanced the bond stress and improved the corrosion resistance of the specimens.

4. The bond strength of the tested specimens increased with the increase in the volume content of steel fibres in the geopolymer concrete. The addition of 2\% MIS, $2 \%$ DES and 2\% HYS (1\% MIS and 1\% DES) fibres by volume achieved an increase in the bond strength by $38.27 \%, 32.86 \%$ and $65.98 \%$, respectively, compared to the control plain geopolymer concrete specimen (Specimen GC). Due to the accelerated corrosion process, the bond strength of fibre reinforced geopolymer concrete with 2\% MIS, 2\% DES and 2\% HYS (1\% MIS and 1\% DES) fibres by volume reduced by $54.92 \%, 60.54 \%$ and $38.84 \%$, respectively.

The steel fibre reinforced geopolymer concrete exhibited better resistance to corrosion 491 induced damage than plain geopolymer concrete specimens. The addition of steel fibres to the 492 geopolymer concrete provided positive effects on the control of the corrosion of steel bar and concrete cracking. Steel fibres in geopolymer concrete led to smaller and more closely spaced cracks, which reduced the permeability of the geopolymer concrete.

\section{Acknowledgments}


The authors would like to express their thanks to the staff of the concrete laboratory of the

497 University of Wollongong, Australia for their kind help. The authors also thank the

498

499

500

501

502

503

504

505

506

507

508

509

510

511

512

513

514

515

516

517

518

519

520

521

522

523

Australian Slag Association, Wollongong, Australia for providing aluminosilicate materials necessary for this study. The authors would like to acknowledge the Fibercon Company, Australia for providing deformed macro steel fibres required for this study. The first author is grateful for the financial support received from the Iraqi government for his PhD studies.

\section{References}

1. Turner LK, Collins FG. Carbon dioxide equivalent (CO 2-e) emissions: a comparison between geopolymer and OPC cement concrete. Construction and Building Materials $2013 ; 43: 125-130$.

2. Hardjito D, Wallah SE, Sumajouw DM, Rangan BV. On the development of fly ashbased geopolymer concrete. Materials Journal 2004; 101(6):467-472.

3. McLellan BC, Williams RP, Lay J, Van Riessen A, Corder GD. Costs and carbon emissions for geopolymer pastes in comparison to ordinary portland cement. Journal of Cleaner Production 2011; 19(9):1080-1090.

4. Duxson P, Fernández-Jiménez A, Provis JL, Lukey GC, Palomo A, Van Deventer JSJ. Geopolymer technology: the current state of the art. Journal of Materials Science 2007; 42(9):2917-2933.

5. Al-Majidi MH, Lampropoulos A, Cundy AB. Tensile properties of a novel fibre reinforced geopolymer composite with enhanced strain hardening characteristics. Composite Structures 2017; 168:402-427.

6. Bakharev T. Geopolymeric materials prepared using Class F fly ash and elevated temperature curing. Cement and concrete research 2005; 35(6):1224-1232.

7. Ranjbar N, Mehrali M, Behnia A, Alengaram UJ, Jumaat MZ. Compressive strength and microstructural analysis of fly ash/palm oil fuel ash based geopolymer mortar. Materials \& Design 2014; 59:532-539. 
524

525

526

527

528

529

530

531

532

533

534

535

536

537

538

539

540

541

542

543

544

545

546

547

548

549

550

551

8. Natali A, Manzi S, Bignozzi MC. Novel fiber-reinforced composite materials based on sustainable geopolymer matrix. Procedia engineering 2011; 21:1124-1131.

9. $\mathrm{Ng} \mathrm{TS}$, Amin A, Foster SJ. The behaviour of steel-fibre-reinforced geopolymer concrete beams in shear. Magazine of Concrete Research 2013; 65(5):308-318.

10. Bernal S, De Gutierrez R, Delvasto S, Rodriguez E. Performance of an alkaliactivated slag concrete reinforced with steel fibers. Construction and building Materials 2010; 24(2): 208-214.

11. Chen ZJ. Effect of reinforcement corrosion on the serviceability of reinforced concrete structures. Master's thesis, Department of Civil Engineering, University of Dundee, UK, 2004.

12. Fu XDDL, Chung DDL. Effect of corrosion on the bond between concrete and steel rebar. Cement and Concrete Research 1997; 27(12): 1811-1815.

13. Coccia S, Imperatore S, Rinaldi Z. Influence of corrosion on the bond strength of steel rebars in concrete. Materials and Structures 2016; 49(1-2):537-551.

14. Tondolo F. Bond behaviour with reinforcement corrosion. Construction and Building Materials 2015; 93:926-932.

15. Abosrra L, Ashour AF, Youseffi M. Corrosion of steel reinforcement in concrete of different compressive strengths. Construction and Building Materials 2011; 25(10):3915-3925.

16. Okada K, KobayashiI K, Miyagawa T. Influence of longitudinal cracking due to reinforcement corrosion on characteristics of reinforced concrete members. Structural Journal 1988; 85(2):134-140.

17. Chen G, Hadi MNS, Gao D, Zhao L. Experimental study on the properties of corroded steel fibres. Construction and Building Materials 2015; 79: 165-172.

18. Roque R, Kim N, Kim B, Lopp G. Durability of fiber-reinforced concrete in Florida environments. University of Florida, Tallahassee FL, USA, 2009: 84-85.

19. Grubb JA, Blunt J, Ostertag CP, Devine TM. Effect of steel microfibers on corrosion of steel reinforcing bars. Cement and Concrete Research 2007; 37(7):1115-1126. 
20. Someh AK, Saeki N. The Role of Galvanized Steel Fibers in Corrosion-Protection of Reinforced Concrete. Proceedings of Japan Concrete Institute 1997; 19(1):889-894.

21. Sofi M, Van Deventer JSJ, Mendis PA, Lukey GC. Bond performance of reinforcing bars in inorganic polymer concrete (IPC). Journal of Materials Science 2007; 42(9): 3107-3116.

22. Sarker PK. Bond strength of reinforcing steel embedded in fly ash-based geopolymer concrete. Materials and structures 2011; 44(5):1021-1030.

23. Castel A, Foster SJ. Bond strength between blended slag and Class F fly ash geopolymer concrete with steel reinforcement. Cement and Concrete Research $2015 ; 72: 48-53$.

24. Hamad BS, Ali AYH, Harajli MH. Effect of fiber-reinforced polymer confinement on bond strength of reinforcement in beam anchorage specimens. Journal of Composites for Construction 2005; 9(1):44-51.

25. Tekle BH, Khennane A, Kayali O. Bond of spliced GFRP reinforcement bars in alkali activated cement concrete. Engineering Structures 2017; 147:740-751.

26. Australasian Slag Association, Australasian Slag Association, Wollongong, NSW 2500. http://www.asa-inc.org.au/ground-granulated-blast-furnace-slag.php, 2017 (accessed on 5 December 2017).

27. Eraring Australia, Eraring power station Australia, Level 16, 227 Elizabeth Street Sydney NSW 2000. https://www. originenergy.com.au/about/who-we-are/what wedo/generation.html, 2017 (accessed on 5 December 2017).

28. ASTM C618, Standard specification for coal fly ash and raw or calcined natural pozzolan for use in concrete. ASTM International; 2005.

29. PQ Australia, PQ Australia Limited, 8/10 Riverside Rd, Chipping Norton NSW 2170, 2017 (accessed on 5 December 2017).

30. BASF Australia, BASF Australia Limited, 521 Kororoit Creek Rd, Altona VIC 3018. www.basf.com.au, 2017 (accessed on 5 December 2017).

31. Ganzhou Daye Metallic Fibres Company. WSF Steel Fiber http://www.gzdymf.com/ product/WSF_Steel_Fiber.html, 2017 (accessed on 5 December 2017). 
581 32. Fibercon, http://www.fibercon.com.au, 2017 (accessed on 5 December 2017)

582

583

584

585

586

587

588

589

590

591

592

593

594

595

596

597

598

599

600

601

602

603

604

605

606

607

608

609

610

33. AS 1391-2007. Standard A. Metallic materials-tensile testing at ambient temperature, Australia Standard, Sydney, NSW, 2007.

34. EN-10080. Bond test for ribbed and indented reinforcing steel-pull-out test, European committee for standardization, 2005.

35. Hadi MNS, Farhan NA, Sheikh MN. Design of geopolymer concrete with GGBFS at ambient curing condition using Taguchi method. Construction and Building Materials 2017 ; 140:424-431.

36. Fang C, Lundgren K, Chen L, Zhu C. Corrosion influence on bond in reinforced concrete. Cement and concrete research 2004; 34(11): 2159-2167.

37. Yalciner H, Eren O, Sensoy S. An experimental study on the bond strength between reinforcement bars and concrete as a function of concrete cover, strength and corrosion level. Cement and Concrete Research 2012; 42(5):643-655.

38. Ma Y, Guo Z, Wang L, Zhang J. Experimental investigation of corrosion effect on bond behavior between reinforcing bar and concrete. Construction and Building Materials 2017; 152:240-249.

39. Badawi M, Soudki K. Control of corrosion-induced damage in reinforced concrete beams using carbon fiber-reinforced polymer laminates. Journal of composites for construction 2005; 9(2):195-201.

40. El Maaddawy TA, Soudki KA. Effectiveness of impressed current technique to simulate corrosion of steel reinforcement in concrete. Journal of materials in civil engineering 2003; 15(1):41-47.

41. AS 1012.9-1999, Methods of Testing Concrete-Determination of the Compressive Strength of Concrete Specimens, Standards Australia Limited, Sydney, 1999.

42. AS 1012.10-2000, Methods of Testing Concrete - Determination of Indirect Tensile Strength of Concrete Cylinders (Brasil or Splitting Test), Standards Australia Limited, Sydney, R2014.

43. Sahmaran M, Li VC, Andrade C. Corrosion resistance performance of steelreinforced engineered cementitious composite beams. Materials Journal 2008; 105(3):243-250. 
List of Tables

622 Table 1 Chemical compositions (mass \%) of GGBS and FA.

623 Table 2 Properties of steel fibres.

624 Table 3 Mix proportion of geopolymer concrete [35].

625 Table 4 Test matrix.

626 Table 5 Properties of geopolymer concrete without and with steel fibres.

627 Table 6 Calculated and measured corrosion level.

628 Table 7 Results of pull-out tests for geopolymer concrete mixes. 


\section{List of Figures}

663 Fig. 1 Schematic of the test specimens: (a) Elevation and (b) Plan (Dimensions are in mm).

664 Fig. 2 Pull-out test specimens.

665 Fig. 3 Schematic of the accelerated corrosion test set-up.

666 Fig. 4 Specimens during accelerated corrosion test.

667 Fig. 5 Pull-out test: (a) Schematic diagram and (b) Actual setup.

668 Fig. 6 Variation of current with time: (a) Geopolymer concrete specimens without and with 669 MIS fibres, (b) Geopolymer concrete specimens without and with DES fibres, and (c) 670 Geopolymer concrete specimens without and with HYS fibres.

671 Fig. 7 Non-corroded and corroded reinforcing steel bars.

672 Fig. 8 Specimens before and after the corrosion process: (a) Specimen GC, (b) Specimen 673 GCMIS2, (c) Specimen GCDES2, and (d) Specimen GCHYS2b.

674 Fig. 9 Failure pattern: (a) Specimen GC, (b) Specimen GCMIS2, (c) Specimen GCDES2, and 675 (d) Specimen GCHYS2b.

676 Fig. 10 General behaviour of bond stress versus slip. 
Fig. 11 Bond stress versus slip for non-corroded: (a) Specimens GC and GCMIS, (b)

678 Specimens GC and GCDES, and (c) Specimens GC and GCHYS.

679 Fig. 12 Bond stress versus slip for corroded: (a) Specimens GC and GCMIS, (b) Specimens 680 GC and GCDES, and (c) Specimens GC and GCHYS.

681

682

683

684

685

686

687

688

689

690

691

692

\section{Table 1}

Chemical compositions (mass \%) of GGBS and FA.

\begin{tabular}{lll}
\hline Component & GGBS & FA \\
\hline $\mathrm{SiO}_{2}$ & 32.40 & 62.2 \\
$\mathrm{Al}_{2} \mathrm{O}_{3}$ & 14.96 & 27.5 \\
$\mathrm{Fe}_{2} \mathrm{O}_{3}$ & 0.83 & 3.92 \\
$\mathrm{CaO}$ & 40.70 & 2.27 \\
$\mathrm{MgO}$ & 5.99 & 1.05 \\
$\mathrm{~K}_{2} \mathrm{O}$ & 0.29 & 1.24 \\
$\mathrm{Na}_{2} \mathrm{O}$ & 0.42 & 0.52 \\
$\mathrm{TiO}_{2}$ & 0.84 & 0.16 \\
$\mathrm{P}_{2} \mathrm{O}_{5}$ & 0.38 & 0.30 \\
$\mathrm{Mn}_{2} \mathrm{O}_{3}$ & 0.40 & 0.09 \\
$\mathrm{SO}_{3}$ & 2.74 & 0.08 \\
$\mathrm{LOI}$ & NA & 0.89 \\
\hline
\end{tabular}




\section{Table 2}

713 Properties of steel fibres.

\begin{tabular}{lcccc}
\hline Type of steel fibre & $\begin{array}{c}\text { Length } \\
(\mathrm{mm})\end{array}$ & $\begin{array}{c}\text { Diameter } \\
(\mathrm{mm})\end{array}$ & $\begin{array}{c}\text { Tensile strength } \\
(\mathrm{MPa})\end{array}$ & $\begin{array}{c}\text { Density } \\
\left(\mathrm{kg} / \mathrm{m}^{3}\right)\end{array}$ \\
\hline Micro steel (MIS) fibres [31] & $6 \pm 1$ & $0.2 \pm 0.05$ & $>2600$ & 7900 \\
$\begin{array}{l}\text { Deformed macro steel (DES) } \\
\text { fibres [32] }\end{array}$ & 18 & 0.55 & 800 & 7865 \\
\hline
\end{tabular}

714

715

716

717

718

719

720 
Table 3

729 Mix proportion of geopolymer concrete [35].

\begin{tabular}{|c|c|}
\hline Geopolymer mix & Quantity \\
\hline FA $\left(\mathrm{kg} / \mathrm{m}^{3}\right)$ & 225 \\
\hline GGBS $\left(\mathrm{kg} / \mathrm{m}^{3}\right)$ & 225 \\
\hline Al/Binder & 0.35 \\
\hline Aggregate $\left(\mathrm{kg} / \mathrm{m}^{3}\right)$ & 1164 \\
\hline Sand $\left(\mathrm{kg} / \mathrm{m}^{3}\right)$ & 627 \\
\hline $\mathrm{Na}_{2} \mathrm{SiO}_{3} / \mathrm{NaOH}$ & 2.5 \\
\hline $\mathrm{Na}_{2} \mathrm{SiO}_{3}\left(\mathrm{~kg} / \mathrm{m}^{3}\right)$ & 112.5 \\
\hline $\mathrm{NaOH}\left(\mathrm{kg} / \mathrm{m}^{3}\right)$ & 45 \\
\hline $\mathrm{NaOH}$ (mole/liter) & 14 \\
\hline Superplasticizer $\left(\mathrm{kg} / \mathrm{m}^{3}\right)$ & 22.5 \\
\hline Water $\left(\mathrm{kg} / \mathrm{m}^{3}\right)$ & 45 \\
\hline
\end{tabular}

730

731 
Table 4

733 Test matrix.

\begin{tabular}{lll}
\hline Concrete mix & Type of steel fibre & Percentage by volume (\%) \\
\hline GC & Plain geopolymer concrete & 0 \\
\hline GCMIS1 & Micro steel fibre (MIS) & $1.5(1.5 \%$ MIS $)$ \\
GCMIS1.5 & & $2(2 \%$ MIS $)$ \\
GCMIS2 & & $1(1 \%$ DES $)$ \\
\hline GCDES1 & Deformed steel fibre (DES) & $1.5(1.5 \%$ DES $)$ \\
GCDES1.5 & $2(2 \%$ DES $)$ \\
GCDES2 & $2(0.5 \%$ MIS+1.5\% DES $)$ \\
\hline GCHYS2a & Hybrid steel fibre (HYS $)$ & $2(1 \%$ MIS+1\% DES $)$ \\
GCHYS2b & $2(1.5 \%$ MIS+0.5\% DES $)$ \\
GCHYS2c & & \\
\hline
\end{tabular}




\section{Table 5}

757 Properties of geopolymer concrete without and with steel fibres.

\begin{tabular}{lcc}
\hline Concrete mix & $\begin{array}{c}\text { Average Compressive } \\
\text { Strength (MPa) at 28 days }\end{array}$ & $\begin{array}{c}\text { Average Splitting Tensile } \\
\text { Strength (MPa) at 28 days }\end{array}$ \\
\hline GC & 41.1 & 3.7 \\
GCMIS1 & 42.7 & 4.0 \\
GCMIS1.5 & 42.8 & 4.9 \\
GCMIS2 & 43.7 & 5.1 \\
GCDES1 & 41.7 & 4.6 \\
GCDES1.5 & 41.9 & 4.8 \\
GCDES2 & 42.6 & 5.3 \\
GCHYS2a & 46.0 & 5.8 \\
GCHYS2b & 47.2 & 6.1 \\
GCHYS2c & 46.3 & 5.6 \\
\hline
\end{tabular}

758

759

760

761

762

763

764

765

766

767

768

769

770

771

772 
Table 6

775 Calculated and measured corrosion level.

\begin{tabular}{lll}
\hline Concrete mix & $\begin{array}{l}\text { Calculated corrosion } \\
(\%)\end{array}$ & $\begin{array}{l}\text { Measured corrosion } \\
(\%)\end{array}$ \\
\hline GC & 6.28 & 5.90 \\
GCMIS1 & 3.36 & 2.25 \\
GCMIS1.5 & 3.18 & 2.85 \\
GCMIS2 & 3.15 & 2.19 \\
GCDES1 & 3.68 & 2.40 \\
GCDES1.5 & 3.30 & 2.31 \\
GCDES2 & 3.22 & 2.13 \\
GCHYS2a & 3.12 & 2.11 \\
GCHYS2b & 2.40 & 1.94 \\
GCHYS2c & 3.14 & 2.04 \\
\hline
\end{tabular}

776

777

778

779

780

781

782

783

784

785 
788 Results of pull-out tests for geopolymer concrete mixes.

\begin{tabular}{lcccc}
\hline & \multicolumn{2}{c}{ Non-corroded specimens } & \multicolumn{2}{c}{ Corroded specimens } \\
\cline { 2 - 5 } Concrete mix & $\begin{array}{c}\text { Maximum } \\
\text { bond stress } \\
(\mathrm{MPa})\end{array}$ & $\begin{array}{c}\text { Slip at maximum } \\
\text { bond stress } \\
(\mathrm{mm})\end{array}$ & $\begin{array}{c}\text { Maximum } \\
\text { bond stress } \\
(\mathrm{MPa})\end{array}$ & $\begin{array}{c}\text { Slip at maximum } \\
\text { bond stress } \\
(\mathrm{mm})\end{array}$ \\
\hline GC & 16.46 & 1.96 & 5.85 & 1.35 \\
GCMIS1 & 21.12 & 2.46 & 8.30 & 2.02 \\
GCMIS1.5 & 21.87 & 2.55 & 8.98 & 2.32 \\
GCMIS2 & 22.76 & 2.98 & 10.26 & 2.89 \\
GCDES1 & 20.56 & 2.44 & 7.38 & 1.42 \\
GCDES1.5 & 21.22 & 2.60 & 7.68 & 1.48 \\
GCDES2 & 21.87 & 2.68 & 8.63 & 2.14 \\
GCHYS2a & 22.88 & 2.94 & 10.75 & 2.68 \\
GCHYS2b & 27.32 & 3.36 & 16.71 & 3.22 \\
GCHYS2c & 23.87 & 3.06 & 11.75 & 2.52 \\
\hline
\end{tabular}

789

790 

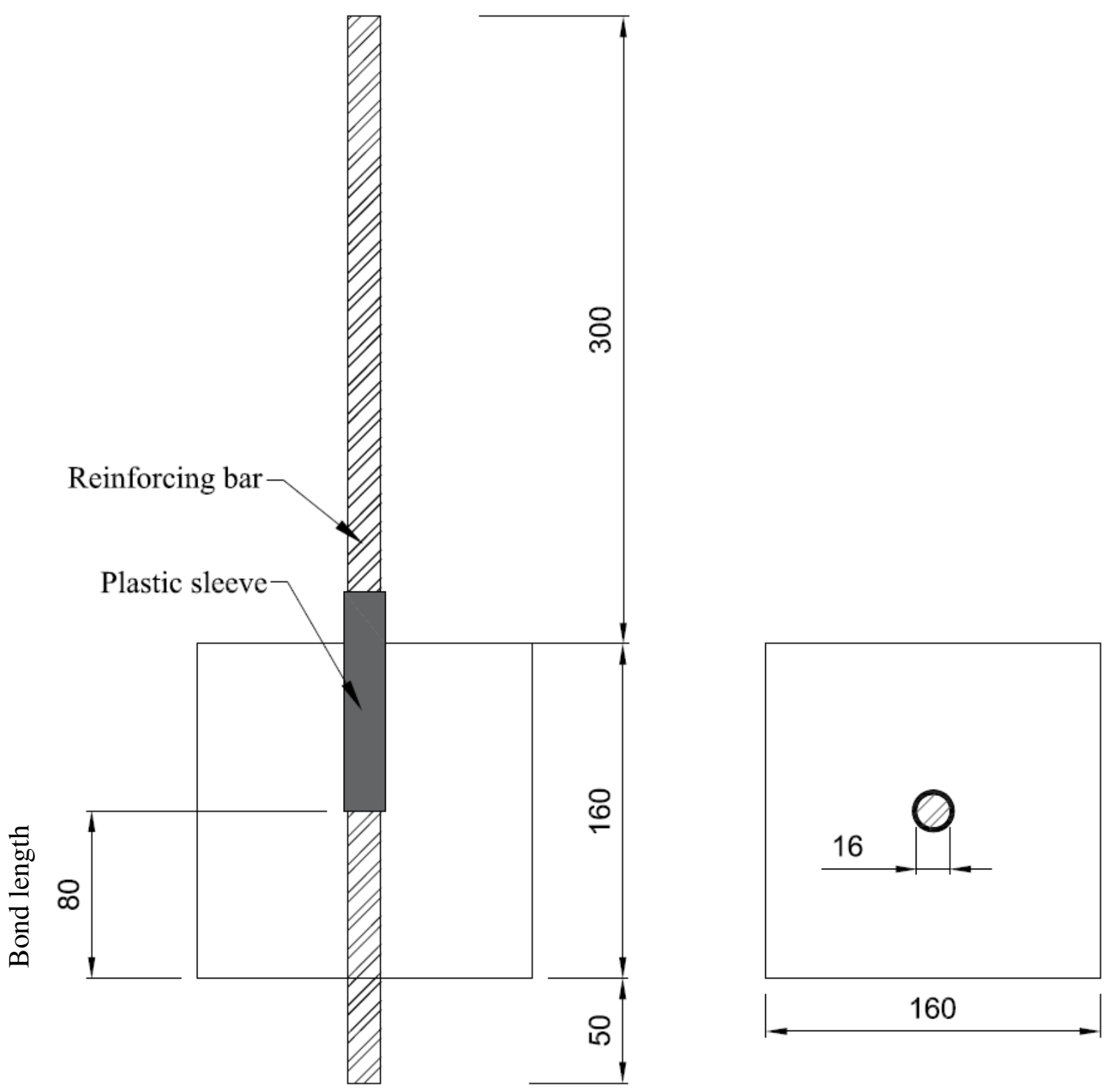

791

792

(a) Elevation

(b) Plan

793

794

Fig. 1. Schematic of the test specimens: (a) Elevation and (b) Plan

795

(Dimensions are in $\mathrm{mm}$ ).

796

797

798 
799

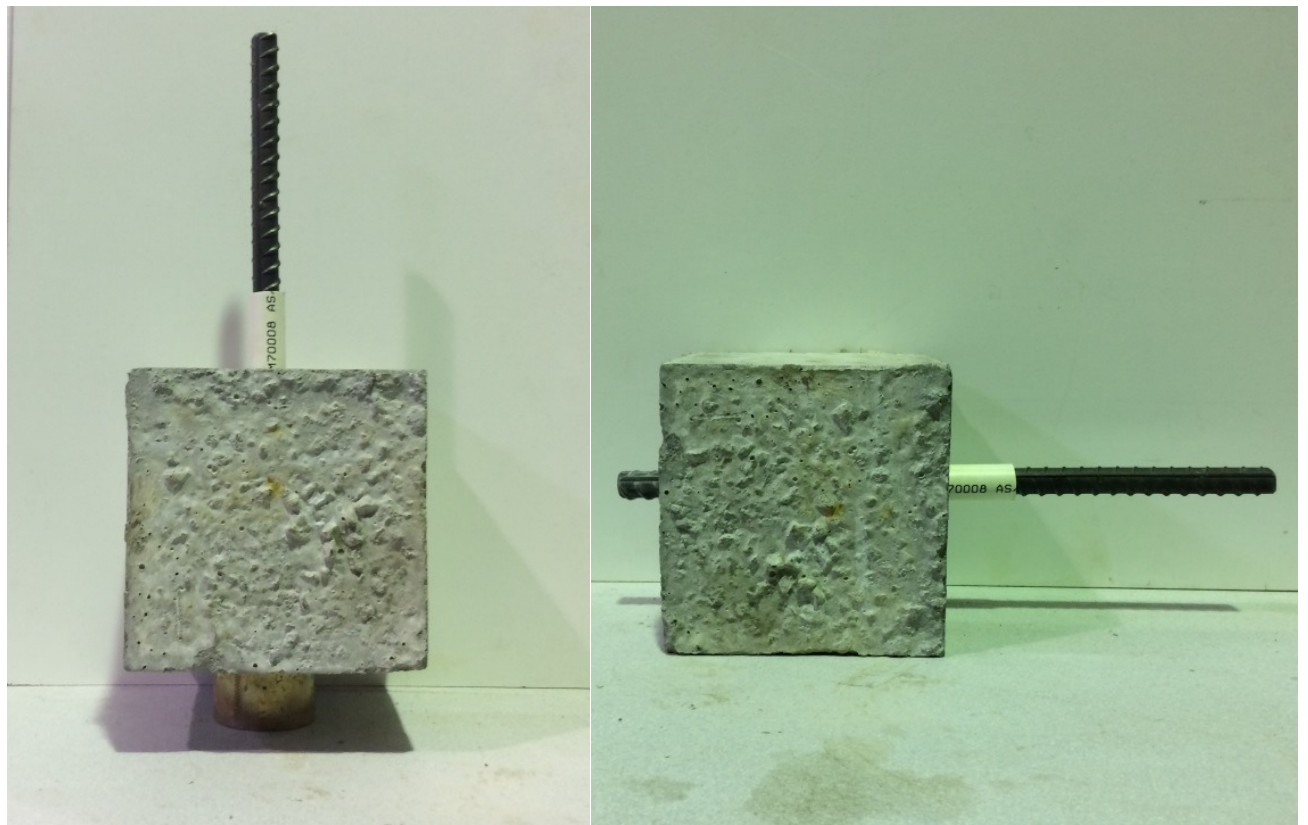

800

Fig. 2. Pull-out test specimens.

801

802

803

804

805

806

807

808

809

810

811

812

813 


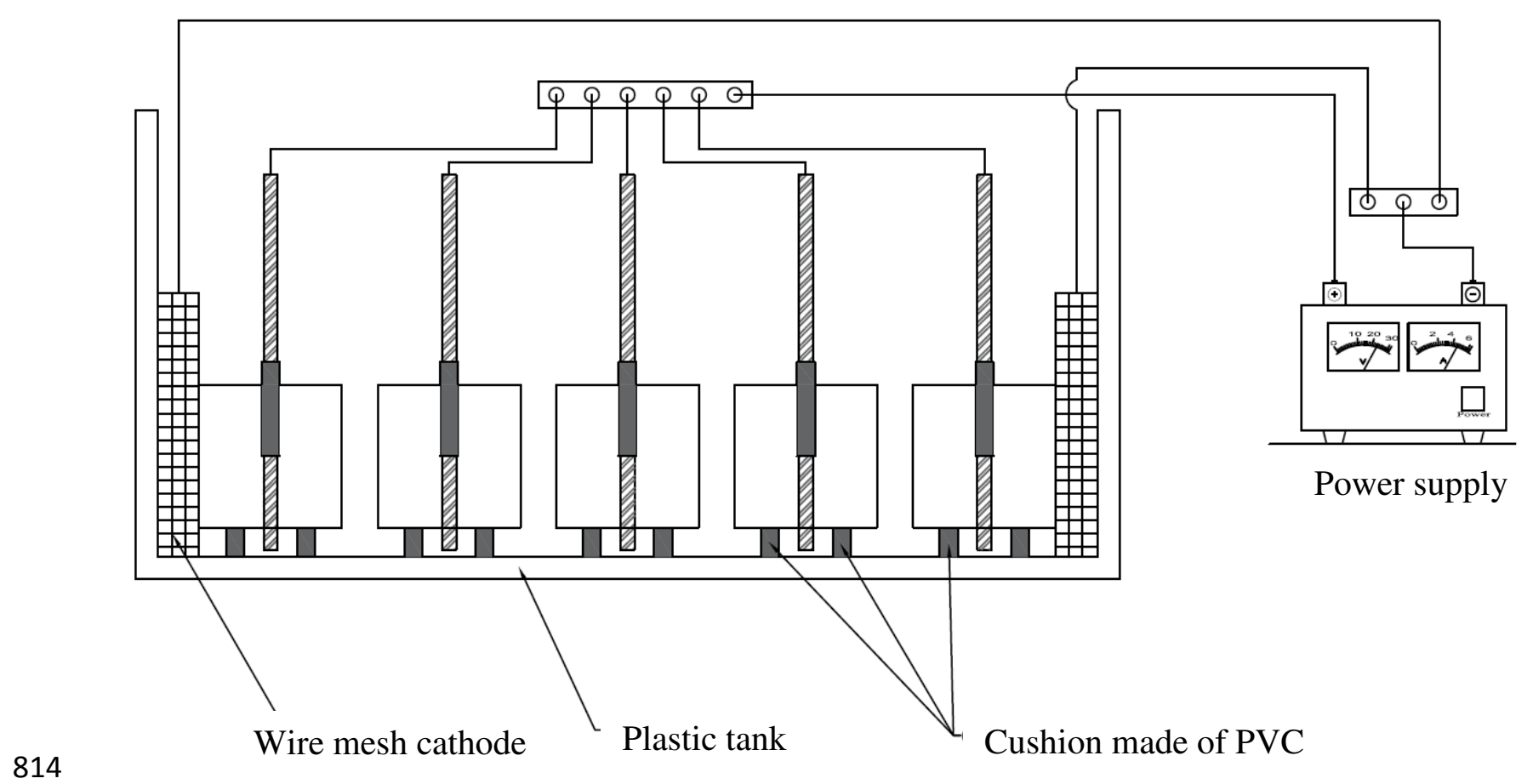

815

Fig. 3. Schematic of the accelerated corrosion test set-up.

816

817

818 


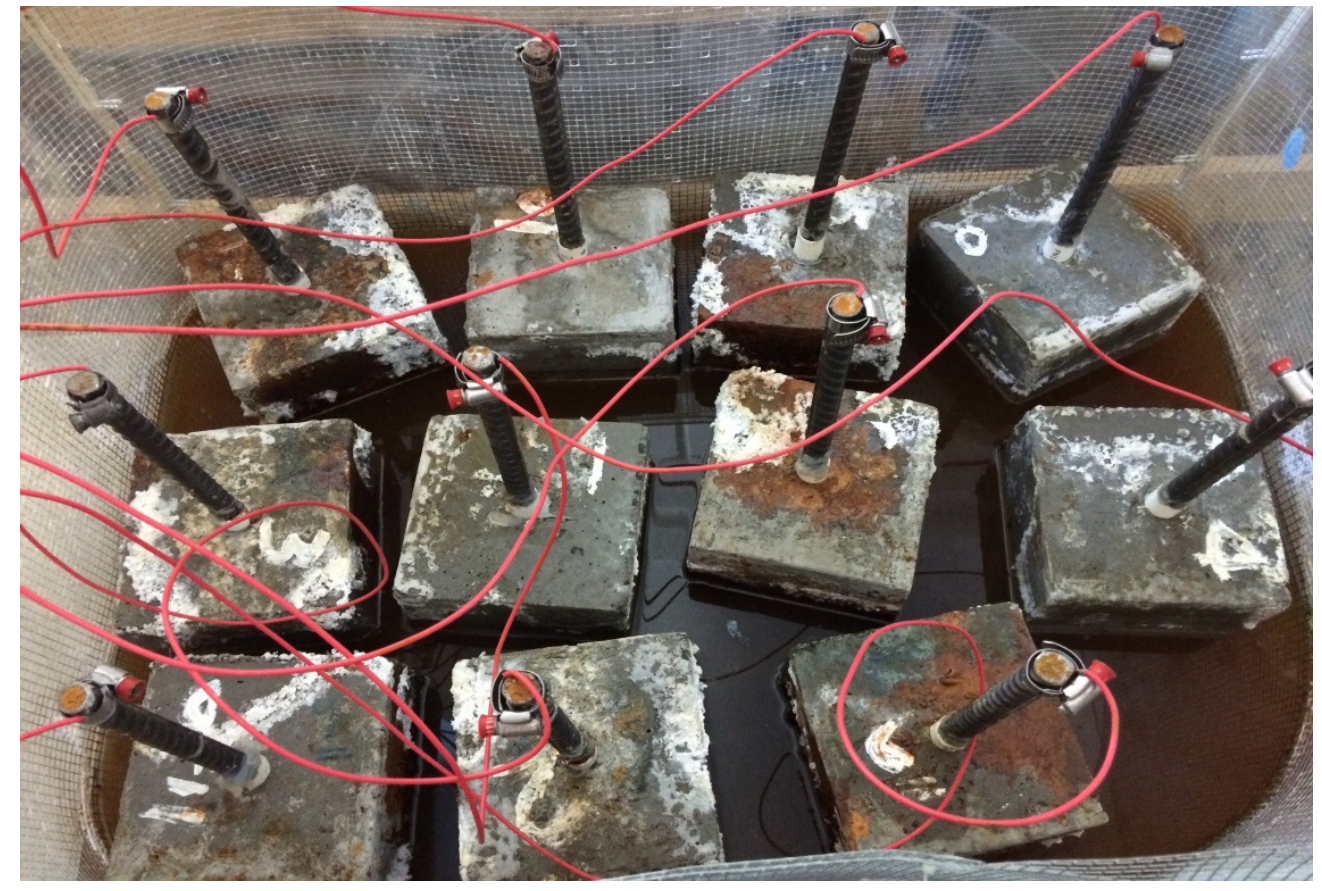

Fig. 4. Specimens during accelerated corrosion test. 


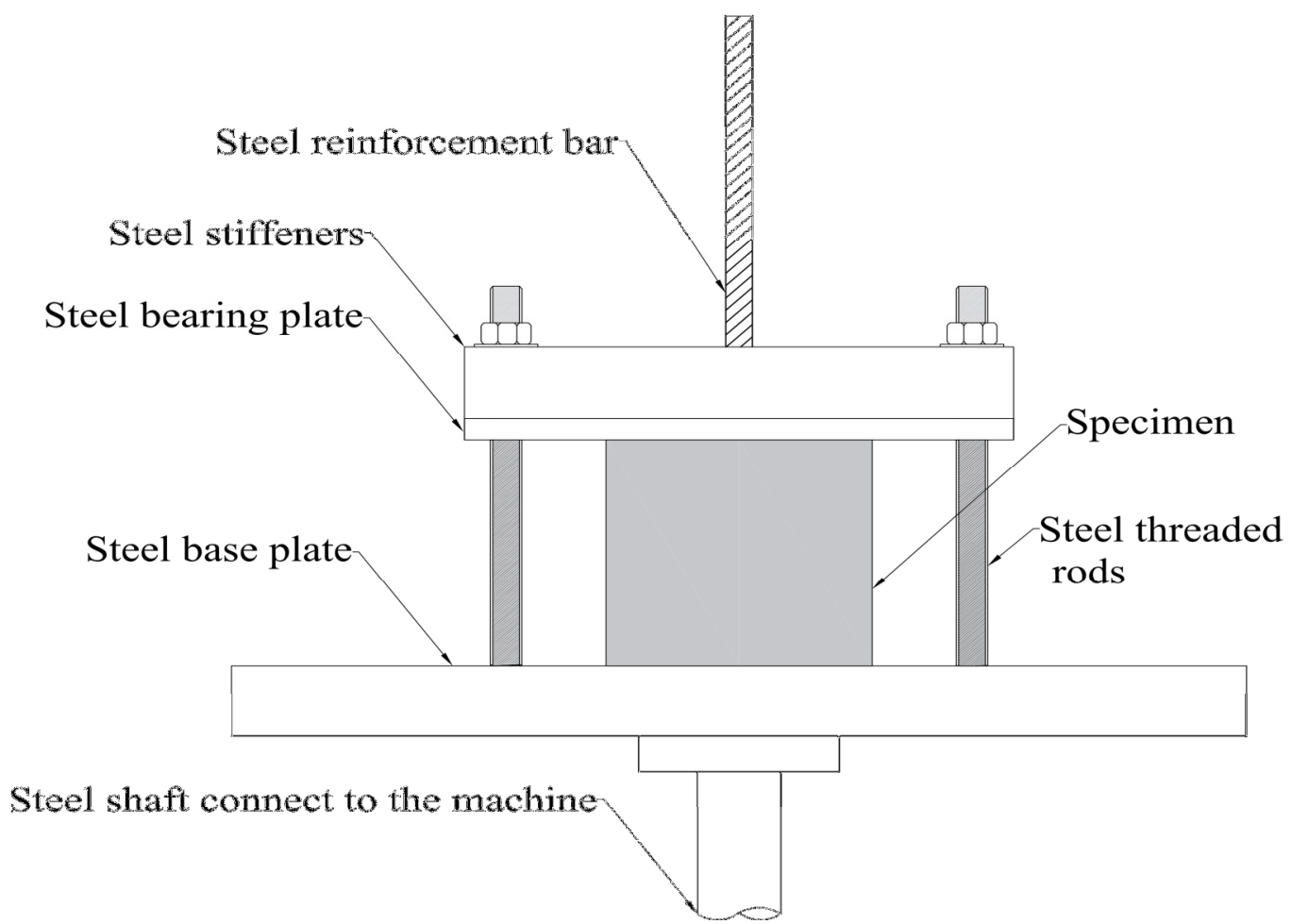

(a)

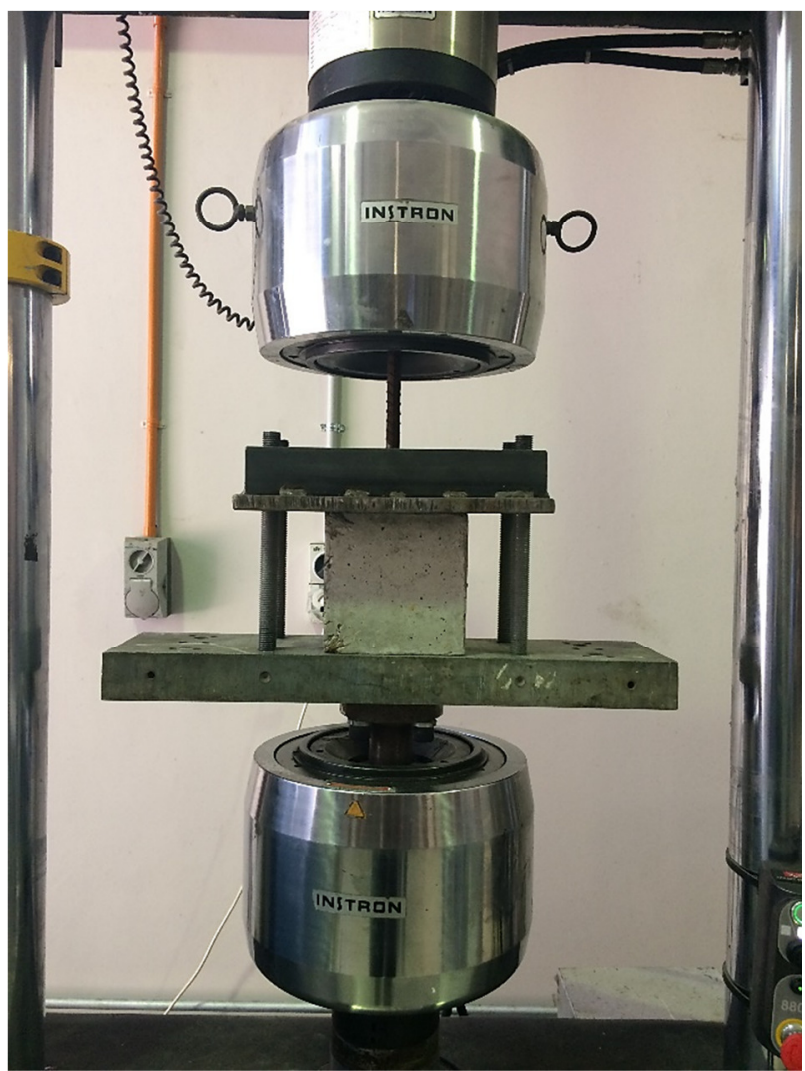

(b)

Fig. 5. Pull-out test: (a) Schematic diagram and (b) Actual setup. 


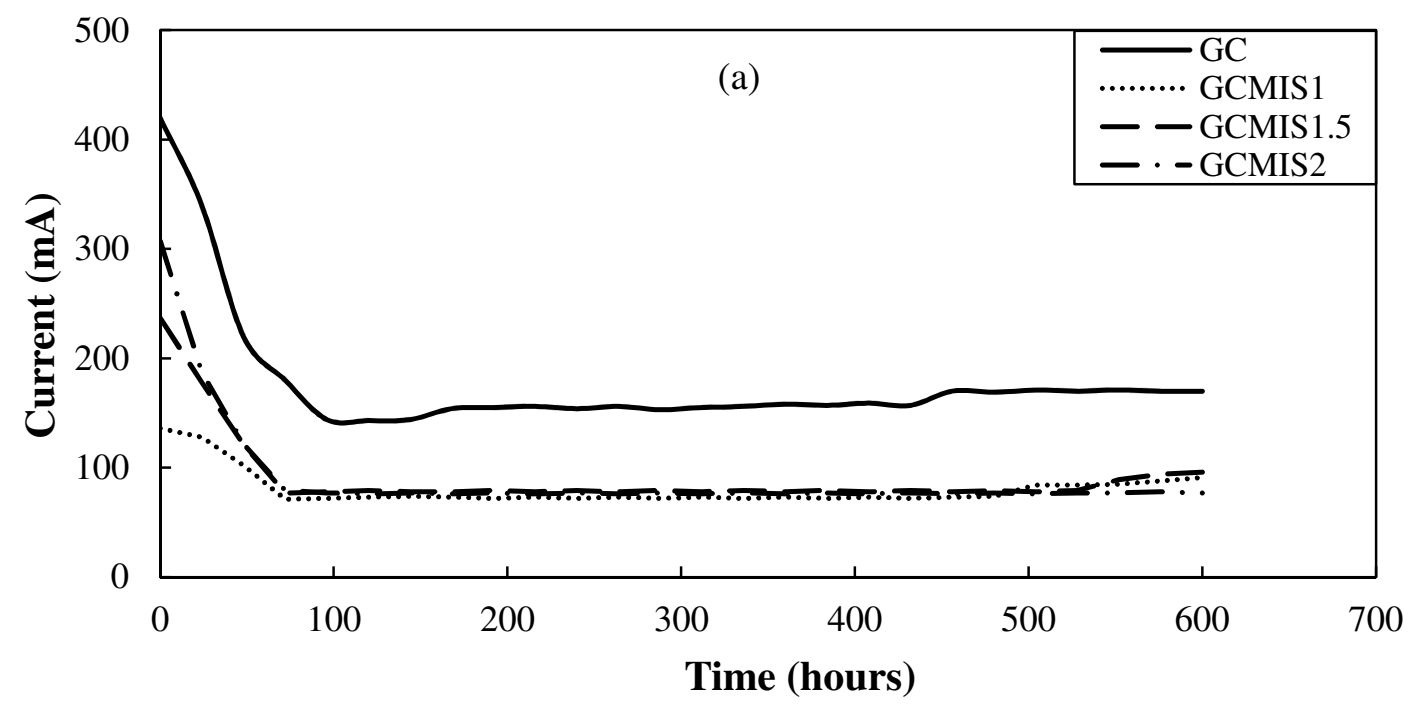

826

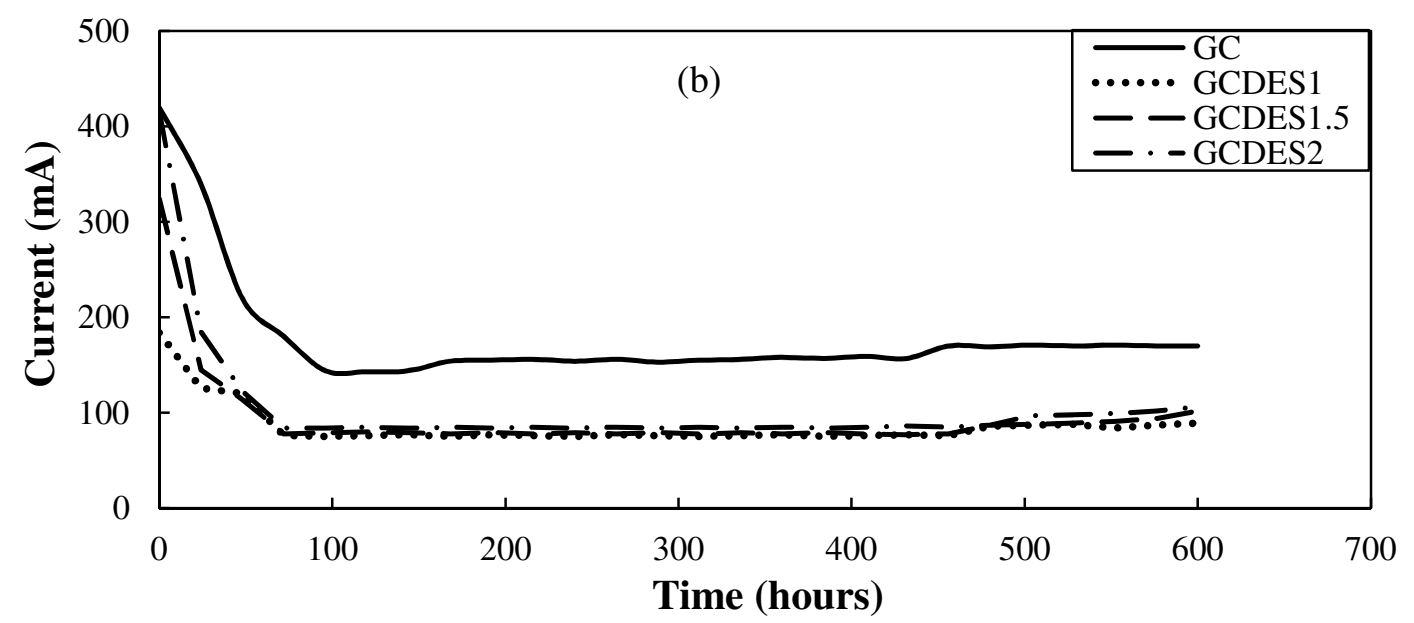

827

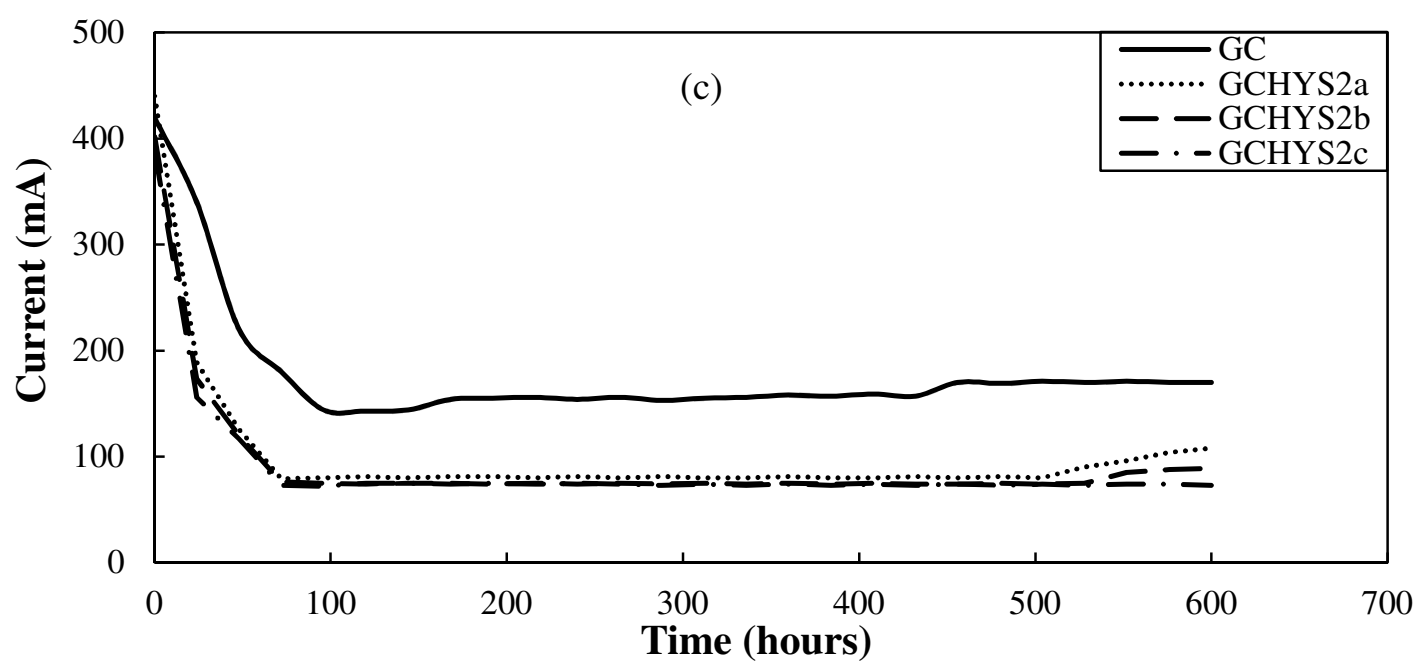

Fig. 6. Variation of current with time: (a) Geopolymer concrete specimens without and with MIS fibres, (b) Geopolymer concrete specimens without and with DES fibres, and (c) Geopolymer concrete specimens without and with HYS fibres. 
835

836

837

838

839

840

841

842

843

844

845

846

847

848

849

850

851

852

853

854

855

856

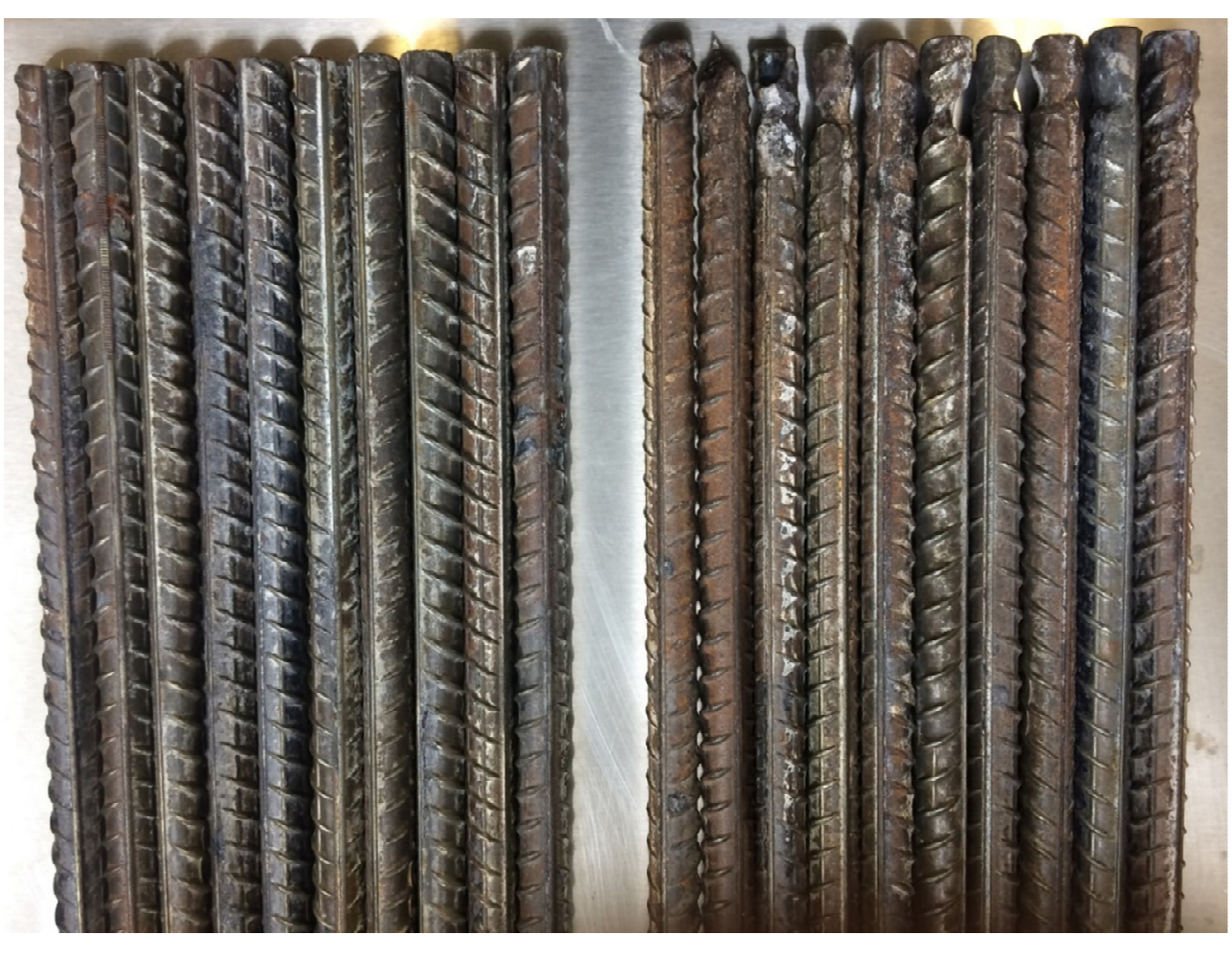

Non-corroded reinforcing steel bars Corroded reinforcing steel bars

Fig. 7. Non-corroded and corroded reinforcing steel bars. 
857

858

859

860

861

862

863

864

865

866

867

868

869

870

871

872

873

874

875

876

877

878

879

880

881

882

883

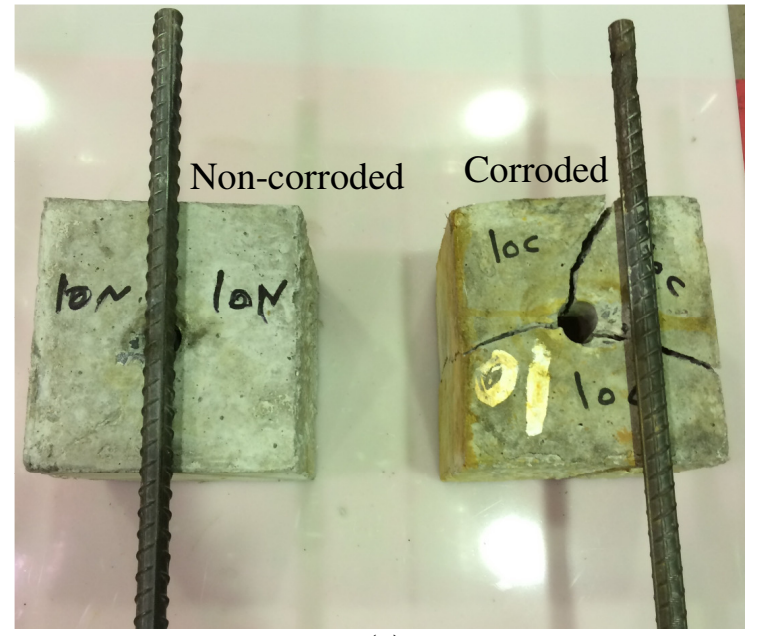

(a)

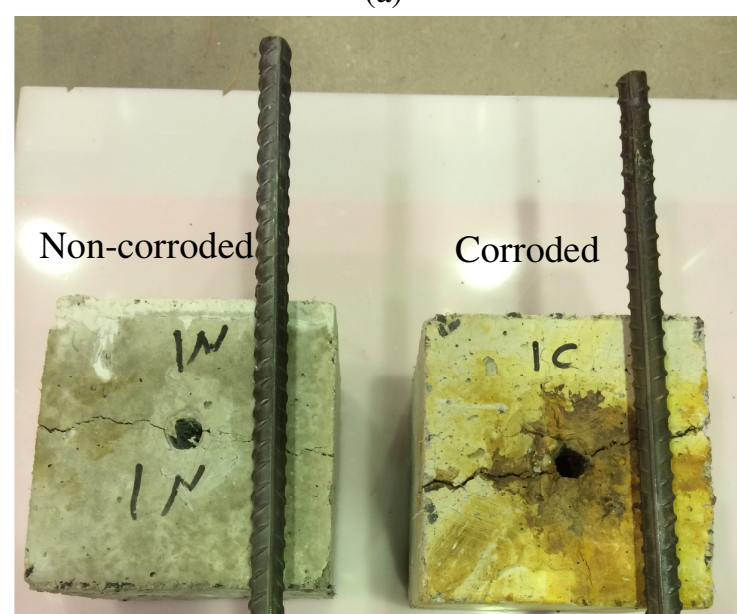

(c)

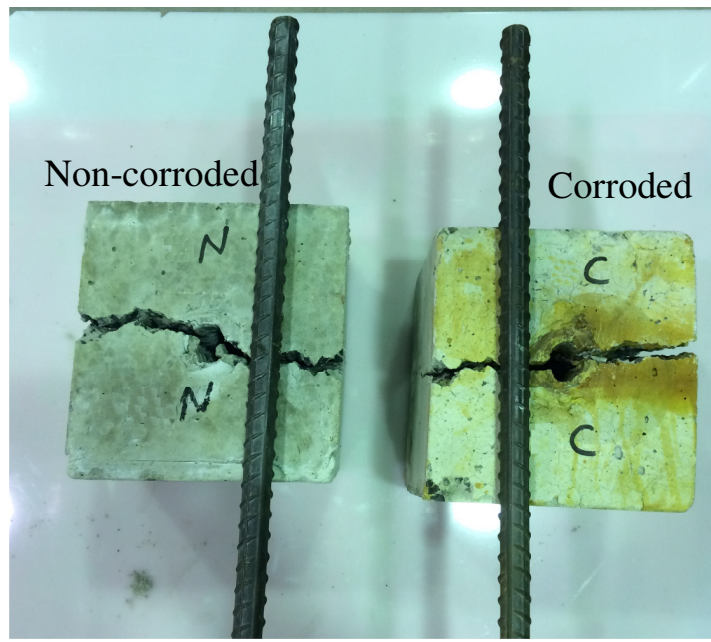

(b)

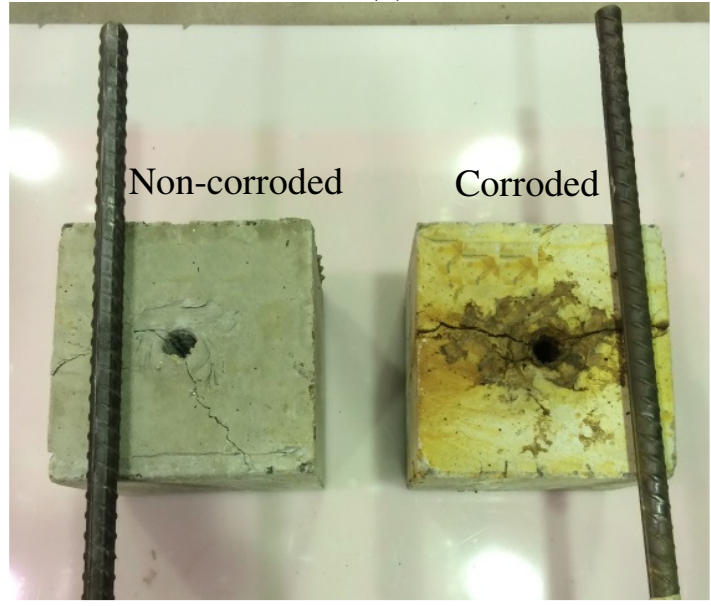

(d)

Fig. 8. Specimens before and after the corrosion process: (a) Specimen GC, (b) Specimen GCMIS2, (c) Specimen GCDES2, and (d) Specimen GCHYS2b. 


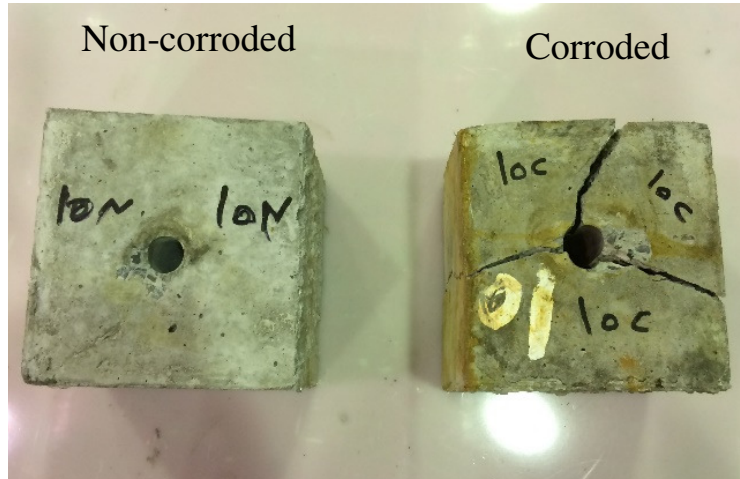

(a)

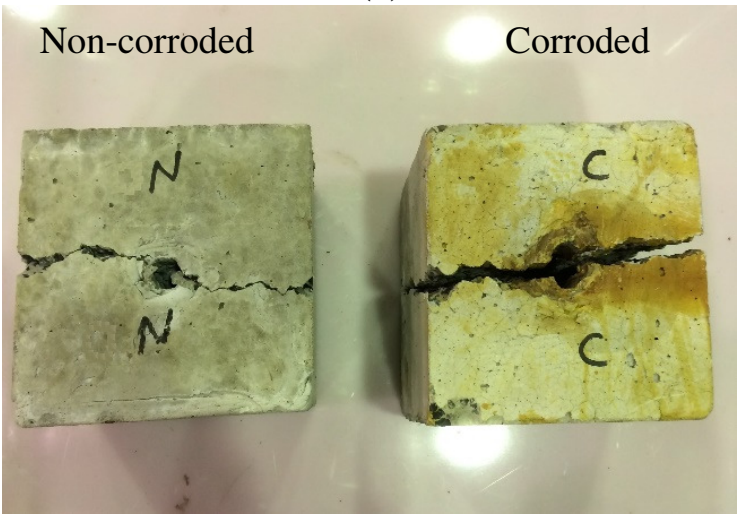

(b)

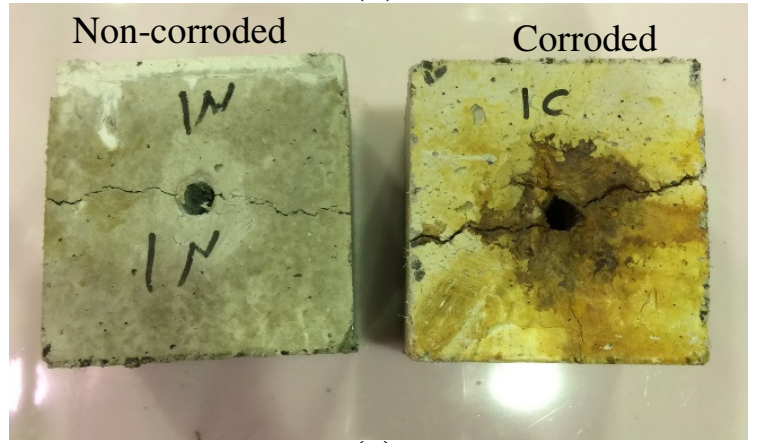

(c)

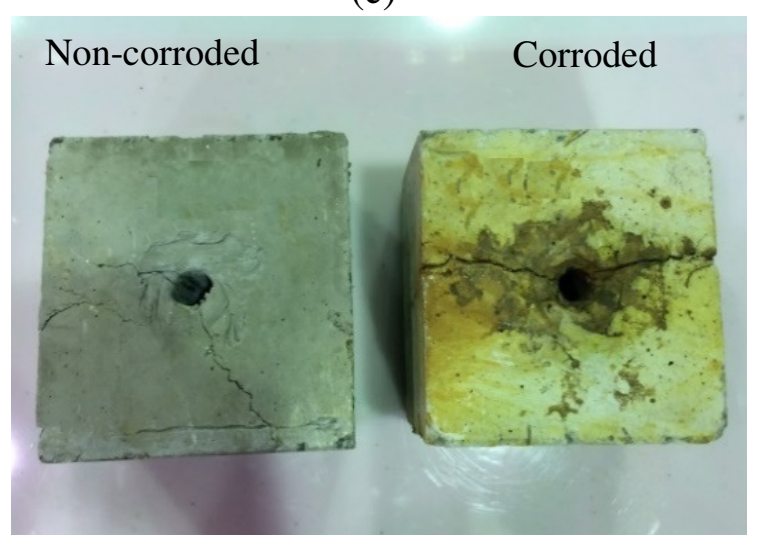

(d)

Fig. 9. Failure pattern: (a) Specimen GC, (b) Specimen GCMIS2, (c) Specimen GCDES2, and (d) Specimen GCHYS2b. 


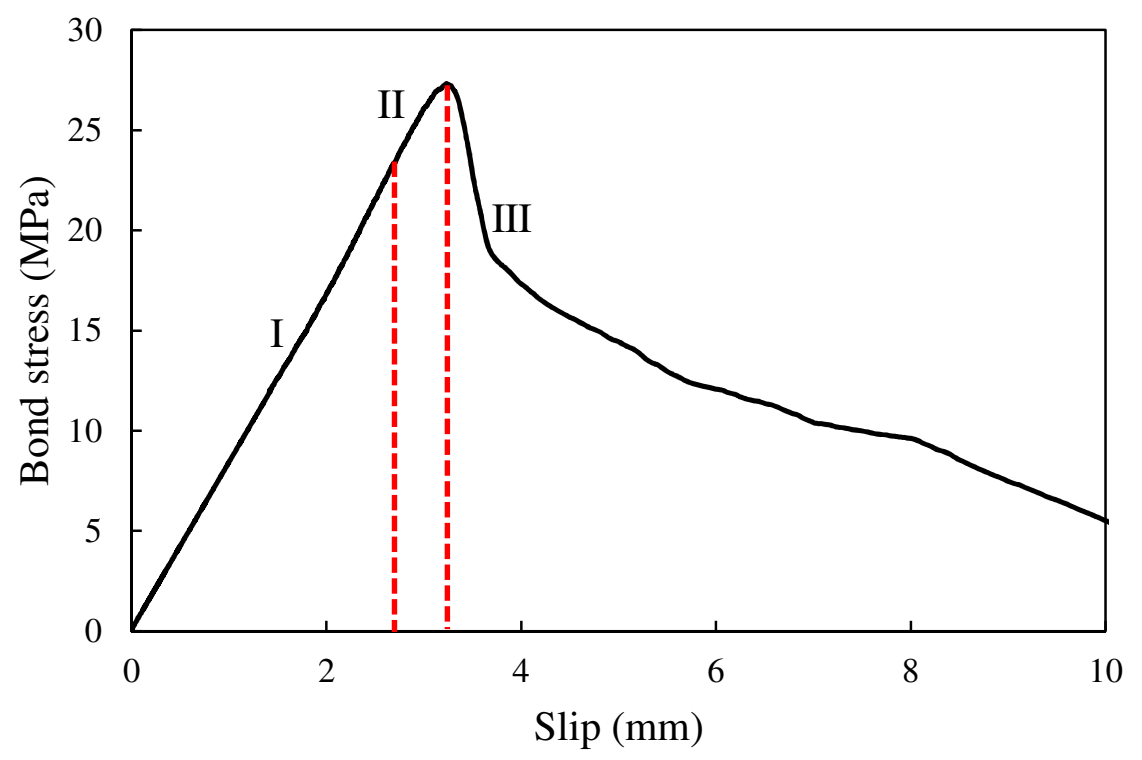

892

893

Fig. 10. General behaviour of bond stress versus slip.

894

895

896

897

898

899

900

901

902

903

904 


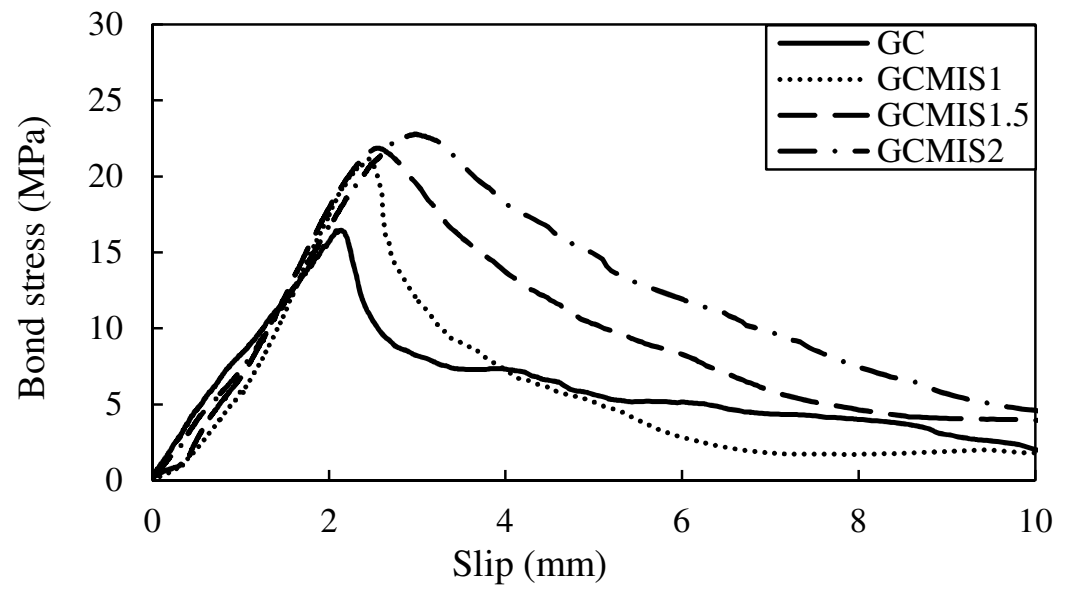

(a) Specimens GC and GCMIS.

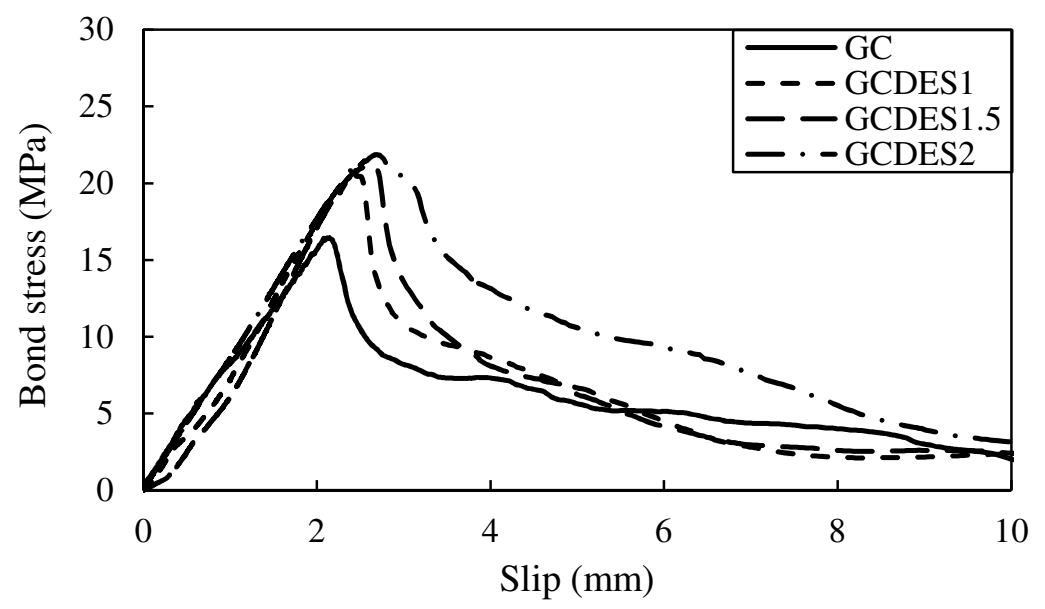

(b) Specimens GC and GCDES.

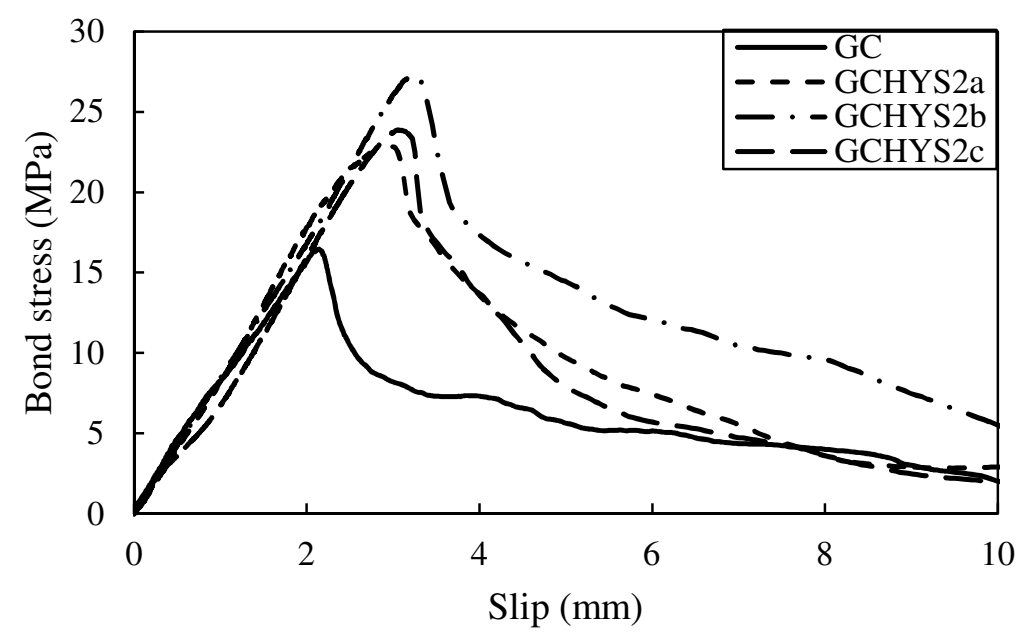

(c) Specimens GC and GCHYS. 


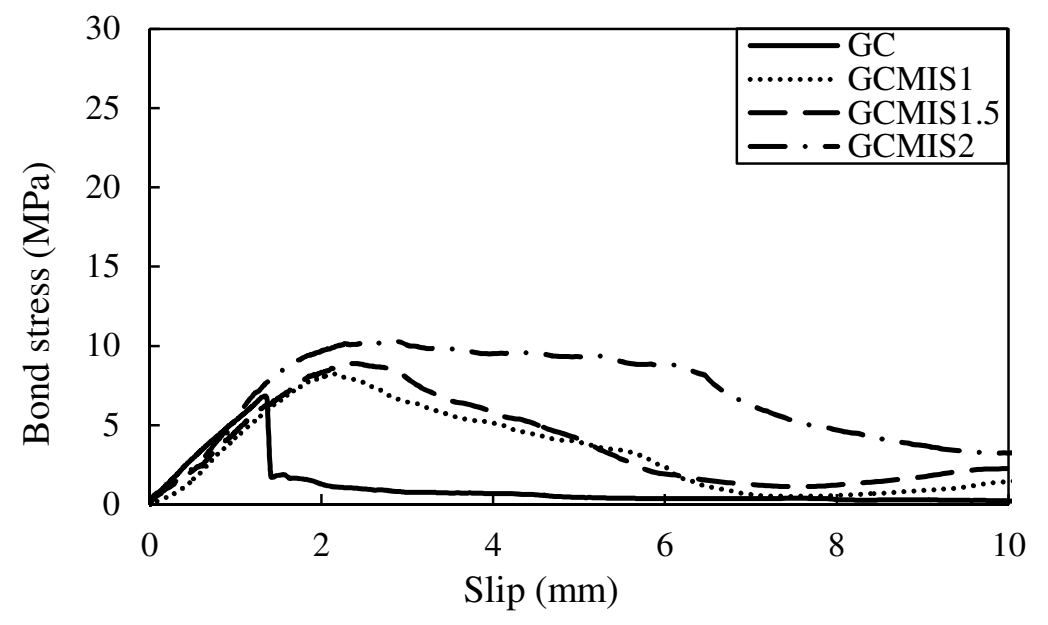

(a) Specimens GC and GCMIS.

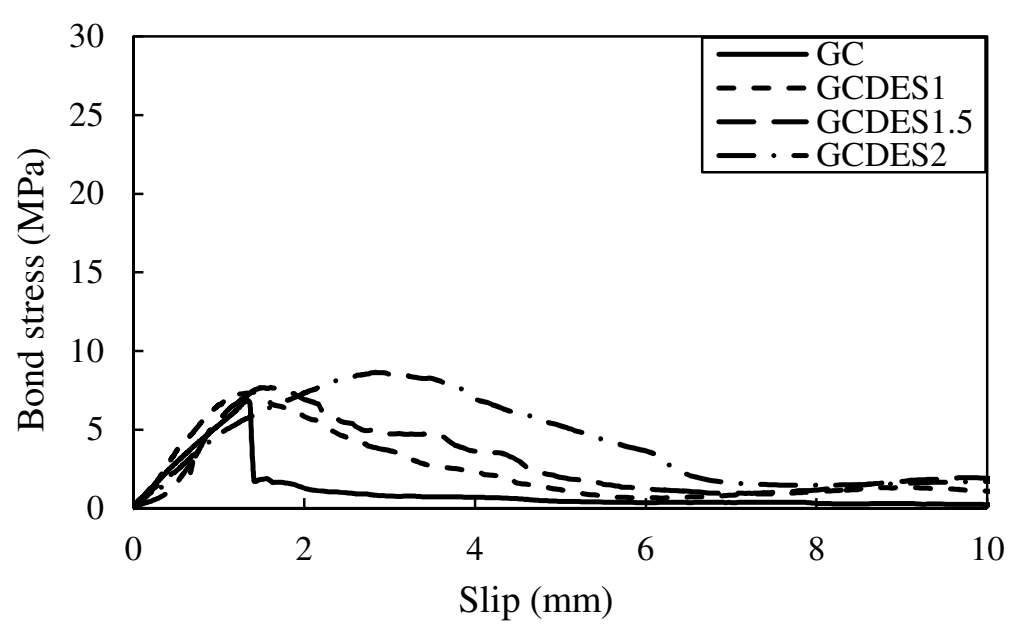

(b) Specimens GC and GCDES.

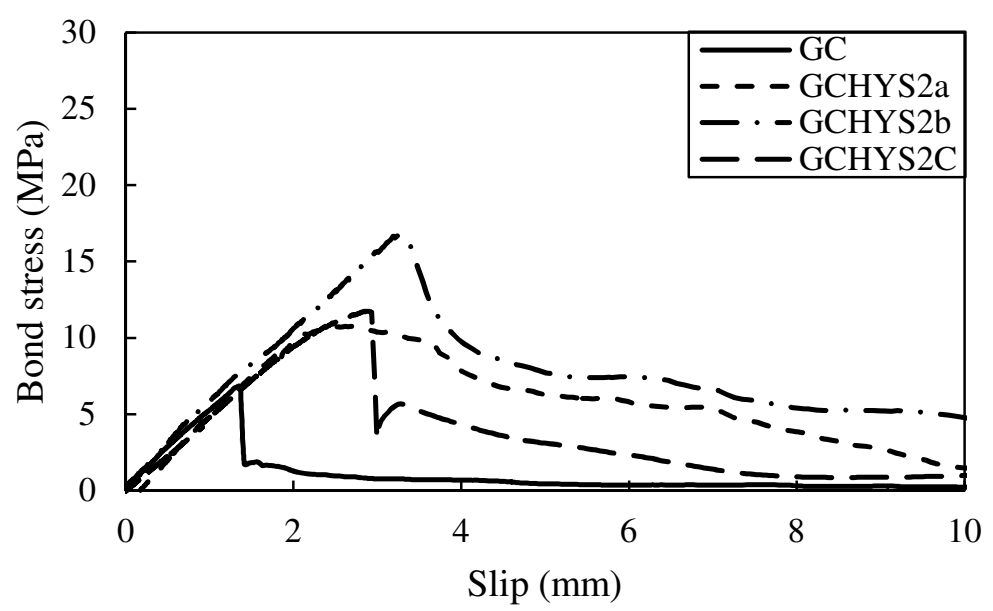

(c) Specimens GC and GCHYS.

Fig. 12. Bond stress versus slip for corroded: (a) Specimens GC and GCMIS, (b) Specimens

GC and GCDES, and (c) Specimens GC and GCHYS. 